\title{
OLD-AGE LABOR FORCE PARTICIPATION IN GERMANY: WHAT EXPLAINS THE TREND REVERSAL AMONG OLDER MEN? AND WHAT THE STEADY INCREASE AMONG WOMEN?
}

\author{
Axel Börsch-Supan \\ Irene Ferrari \\ Working Paper 24044 \\ http://www.nber.org/papers/w24044 \\ NATIONAL BUREAU OF ECONOMIC RESEARCH \\ 1050 Massachusetts Avenue \\ Cambridge, MA 02138 \\ November 2017
}

The views expressed herein are those of the authors and do not necessarily reflect the views of the National Bureau of Economic Research.

NBER working papers are circulated for discussion and comment purposes. They have not been peer-reviewed or been subject to the review by the NBER Board of Directors that accompanies official NBER publications.

(C) 2017 by Axel Börsch-Supan and Irene Ferrari. All rights reserved. Short sections of text, not to exceed two paragraphs, may be quoted without explicit permission provided that full credit, including $(\odot$ notice, is given to the source. 
Old-age Labor Force Participation in Germany: What Explains the Trend Reversal among Older Men? And What the Steady Increase among Women?

Axel Börsch-Supan and Irene Ferrari

NBER Working Paper No. 24044

November 2017

JEL No. H55,J14,J26

\begin{abstract}
The aim of this paper is to illustrate for Germany the factors that may explain the U-shaped pattern of older men's labor force participation - from a long declining trend that began in the early 1970s to an increasing trend starting from the late 1990s - and at the same time the steady increase in older women's labor force participation. In a first step, we provide graphical evidence of the trends of various variables which may be relevant, with the aim of investigating the presence or absence of common patterns between these factors and labor force participation. Then, through a decomposition analysis, we provide an empirical estimate of the contribution of some of these factors to the overall evolution of labor force participation. Our preliminary conclusion is that much of the change in the trend of older men's labor force participation may be explained by changes in public pension regulations, and in particular by the phasing in of actuarial adjustments for early retirement. Regarding women, whether public pension rules play a role is unclear. Most probably, the secular change of women's role in society is the main driver of the steadily increasing labor force participation among German women.
\end{abstract}

Axel Börsch-Supan

Munich Center for the Economics of Aging

Max Planck Institute

for Social Law and Social Policy

Amalienstrasse 33

80799 Munich

GERMANY

and NBER

boersch-supan@mea.mpisoc.mpg.de

Irene Ferrari

Munich Center for the Economics of Aging

Max Planck Institute

for Social Law and Social Policy

Amalienstrasse 33

80799 Munich

GERMANY

ferrari@mea.mpisoc.mpg.de 


\section{Introduction}

A common finding among most industrialized countries is the increase in older men's labor force participation since around the late 1990s which is a stunning reversal from the long declining trend that began in the early 1970s. There are many factors that have been mentioned in the literature that may help explaining this U-shaped pattern. In previous books of this series it has been extensively shown, through descriptive evidence, case studies and formal micro-econometric analyzes, how changes in public pension and disability insurance laws affect the retirement behavior of German workers (see Börsch-Supan et al. 1999, 2004, 2012). Improved health and longevity are two other factors that have been analyzed in this series, and which seem natural candidates contributing to labor force participation decisions of older workers (see Börsch-Supan et al. 2012, 2016). Among other factors that have been suggested in the literature, the most cited are increased educational attainment, the shift towards less physically demanding jobs, couples’ joint retirement decisions and labor demand factors, like increasing real wages and decreasing unemployment. Given that the population is projected to continue ageing in the future ${ }^{1}$, it is important to study the role of each factor in order to understand whether the current rising trend in labor force participation will continue, thus reducing the negative consequences of ageing on fiscal sustainability, or whether it is going to slow down.

In this chapter, we will try to give an overall assessment of the relative contribution of these factors. We will first provide graphical evidence of the trends of various variables which may be relevant, with the aim of investigating the presence or absence of common patterns between these factors and labor force participation. Then, through a decomposition analysis, we will provide an empirical estimate of the contribution of some of these factors to the overall evolution of labor force participation. This allows picturing how the labor force participation trend would have looked like if the distribution of any selected individual characteristic had not changed through time. In the analysis we will also underline the differences in labor force participation trends between men and women, trying to shed light on the factors that might have contributed to these differences.

\footnotetext{
${ }^{1}$ A study by the German Federal Statistical Office reports that in 2060 every third person (34\%) will be at least 65 years old and the number of 70 year olds will be twice the number of new-born children (see "Germany's population by 2060 - Results of the 12th coordinated population projection”, Statistisches Bundesamt (2009)).
} 
Given the evidence presented in this work and the results of the previous papers in this series, we believe that, at least as it regards Germany, much of the change in the trend of older men's labor force participation registered in the mid-90s may be explained by changes in public pension regulations, and in particular by the phasing in of actuarial adjustments for early retirement. In fact, even if many of the variables studied may have contributed to the overall level of labor force participation, their trend do not show the U-shape pattern observed for labor force participation. Regarding women, things look very different. The labor force participation trend of older women has in fact been continuously rising, as did that of younger women. The secular change of women's role in society seems thus to be the main driver of labor force participation in this case.

\section{The trend towards later retirement}

Figure 1 shows that labor force participation (LFP) in Germany for men at risk of retirement ages $(>=55)$ follows a trend similar to that reported by other industrialized countries. This trend is characterized by a first phase in which LFP was constantly decreasing, followed by a reversal in the trend in the mid-90s and a strong increase in LFP since then, which persists nowadays. Figure 2 shows LFP of women for the same age categories. In this case, rather than a trend reversal, we observe a rather constant increase for the 55-59 age group and a reversal for the 60-64 age group, but much milder than the one characterizing men of the same age.

Figures 1 and 2 are based on the aggregate data provided by the OECD. ${ }^{2}$ Roughly the same patterns are visible in the microdata which GSOEP ${ }^{3}$ provides and which we will use for the detailed analysis in the sequel of this paper, see Figure 3. While the GSOEP survey started only in 1984, the trends for different age categories after that date resemble those obtained using OECD official data and reported in Figure 1.

One may wonder whether the increasing trend in LFP after the age of 55 is only due to cohort effects affecting LFP at younger ages. As regards men, this does not seem the case: as Figure 1 shows, LFP at ages 45-54 not only is not characterized by an increasing trend, but it was actually

\footnotetext{
${ }^{2}$ Dataset: LFS - Sex and Age Indicators, available at: https://stats.oecd.org/.

${ }^{3}$ The German SOcioEconomic Panel is a longitudinal data set resembling the Panel Study of Income Dynamics (PSID) in the US. Our analysis drew on data from 30 waves of the German Socio-Economic Panel Study (SOEP, Version 30, 2015, doi: 10.5684/soep.v30), spanning the period from 1984 until 2013.
} 
slightly decreasing ${ }^{4}$. For women however the LFP pattern at younger ages looks very different from that of men (Figure 2). LFP of women aged 45-54 has been steadily increasing since the 70s, and this may certainly explain at least part of the LFP increase at older ages.

This argument can be more clearly appreciated by looking at Figure 4, which displays ageparticipation profiles by selected cohort groups using the GSOEP data. LFP of men remains basically constant for all birth cohorts considered up until age 55, and start to diverge after this age. LFP of women, on the contrary, is clearly higher the younger the cohort considered, at all ages.

Figure 5 presents the percentage of men and women at ages 50-80 in the labor force for selected years. Also from this perspective, we notice very close patterns for men up until around the age of 55. LFP at older ages is higher now than in 1994, but it was higher in 1984 than in 1994, confirming the trend reversal observed in OECD data. After age 67, however, LFP has barely changed since 2004, and is now at the same level it was in 1984. Again, the picture looks very different for women. In this case, there has been a clear increase in LFP at younger ages, that is however slowing down decade after decade. From the second panel of Figure 5 it is also evident that this increase in LFP is shifted to older ages in the subsequent years. Also for women, after the age of 66 barely any difference can be noticed in age-participation throughout years. Figure 6, finally, shows that LFP of older women is now very close to that for men.

\section{Public pensions in Germany}

In this section we will briefly describe the evolution of the public pension system in Germany, and we will show how this can be related to the trends in LFP. The German pension system covers 85 percent of the German workforce, most of them working in the private sector. The remaining workforce is composed by civil servants, which are covered by a separate and more generous pension system, and self-employed, who are either mandatory participants in occupation-specific pension funds, voluntary participants of the public pension system, self-insured, or a combination thereof. As explained in our previous works (see Börsch-Supan et al. 2012, 2014, 2016), the payas-you-go system was introduced in Germany in 1957, and since the beginning it distinguished

\footnotetext{
${ }^{4}$ The break in the series between 1990 and 1991 is due to the reunification of Germany. From 1991 onwards, data are for unified Germany. See http://www.oecd.org/els/emp/LFSNOTES_SOURCES.pdf.
} 
between old-age pensions and disability pensions. Eligibility for an old-age pension is conditional on reaching the respective early retirement age which has varied greatly over time and across workers while the normal retirement age was 65 for men until recently, see below. In addition, eligibility is conditioned on a minimum number of contribution years which varies by retirement pathway. Eligibility for a disability pension is instead conditional on being partly or fully unable to work and on a small minimum number of contribution years, independent of age. However, the difference in practice between the two is not so clear-cut, as both require 5 years of contributions and the record-based assessment of inability to work may be prone to leniency (see Börsch-Supan et al. 2012). These characteristics of the pension system are reflected in Figures 7 and 8, which show the proportions of workers retiring with each possible pathway. In the 60s, more than half of both men and women were retiring due to disability.

Besides these two major pathways, there are a number of variants of old-age pensions that generally allow lower retirement ages under certain circumstances. Already since 1957, an oldage pension for women and an old-age pension for the unemployed existed that could be drawn at 60 if certain (stricter) contribution requirements were met. Since unemployment was at a historic low in the 1960s and early 1970s (see Figures 22 and 23), retirement via unemployment accounted for a tiny percent of all retirement entries (see Figures 7 and 8). A sizable percent of women was instead retiring early through the old-age pensions for women.

Despite these early retirement possibilities, the 60s were the least generous period in terms of public pension eligibility (Börsch-Supan et al. 2015), and this is reflected in the average retirement ages. Right before the 1972 reform, the average old-age pension retirement ages were 65.1 and 62.7, for men and women respectively. In the case of disability pensions, average retirement age was 57.8 among men and 59.8 among women. As can be seen in Figure 1, LFP of men at the beginning of the 70s was at its highest level in the period considered: almost $90 \%$ for the $55-59$ age category and $72 \%$ for the 60-64 age category. The same picture for women looks somehow different because, as we argued in the previous section, the LFP increase of older women is mainly due to cohort effects, which in turn reflect secular changes in the role of women in the labor market. Despite this, also in the case of women it is possible to notice that LFP did not increase (for the 55-59 age category) and even decreased (for those older than 60) since the beginning of the 70s, without steadily recovering before the mid-90s. 
In 1972, in fact, a new phase begun characterized by increasing the generosity of the pension system. The 1972 reform basically provided new pathways to early retirement: long-term insured individuals could draw old-age pension benefits already at age 63 conditional on at least 35 contribution years without any actuarial adjustment to the retirement age. Besides, it introduced a special old-age pension for disabled workers that could be drawn at age 62 (later at 60), with less stringent health requirements than the disability pension. Figures 7 and 8 show how flexible retirement for long-term insured contributed to the sudden decrease in regular old-age pensions, and also that it partly substituted for the disability pathway. Between 1984 and 1987, the creation of a "bridge to retirement" further increased the incentives to retire early. More generous unemployment benefits were introduced for older workers, which caused a dramatic increase of unemployment rate for this category of workers (see Figures 22 and 23), and substituted for disability pensions.

As a consequence, the average retirement age dropped down to 62.3 and 61.5 years in 1982, for men and women respectively. As these new options partly substituted the disability pathway, the average age of disability retirement started to decrease as well. At the same time, LFP dropped to the minimum of $28.4 \%$ in 1995 for the $60-64$ age category and of $71.3 \%$ in 1994 for the $55-59$ age category.

In 1984, the eligibility requirements for the regular retirement age were reduced from 15 to 5 contribution years, while at the same time eligibility requirements for disability pensions were made less generous. This can again be visualized in Figures 7 and 8, which show (especially for women) an increase in the share of regular old-age pensions, and a contemporaneous decrease in disability pensions, in the years 1984 to 1992.

Due to the threat of demographic change and the risk of the pension system becoming unsustainable, since 1992 a sequence of reforms was enacted which overall cut back on the generosity of the pension system. In 1992, benefits were anchored to net rather than to gross wages and adjustments to the chosen retirement age were introduced gradually between 1998 and 2006. These adjustments, still in place, are not actuarial but amount to $3.6 \%$ for each year of earlier retirement. In 2001, the generosity of the benefits were further reduced by the "Riester factor", while at the same time private "Riester pensions", a form of IRAs, were introduced to offset these 
benefit cuts in the public system. ${ }^{5}$ Further relevant changes were decided in 2004, when the pension benefit indexation formula was modified to account for demographic developments (the "sustainability factor") ${ }^{6}$, and the retirement age for the unemployed was raised to 63: a reduction in the proportion of individuals retiring through this pathway can in fact be seen in Figure 7 after 2004. In 2007, the normal retirement age was gradually increased from 65 to 67 (to be phased in between 2012 and 2029), and retirement ages for other old-age pension pathways were increased as well.

Figure 9 depicts the increase in eligibility ages for the various pathways, with and without deductions. This figure shows that the age increases were mostly effective since 1998, suggesting a possible causal effect on actual retirement ages and on LFP. Figures 10 and 11 show that the average retirement age for old-age pensions has increased by 2 years since 1998, for both men and women. Besides, as noticed above, LFP of workers older than 55 has experienced an increasing trend phase since the mid-90s, and the strongest effect can be observed in the 60-64 age category.

As noticed in our most recent work in this international comparison project (Jürges et al. (2016), in Social Security Programs and Retirement Around the World: The Capacity to Work at Older Ages), it is unclear whether this positive trend will continue in the future or not since this will depend on future changes of the public pension rules. On the one hand, the increase of eligibility age from 65 to 67 should contribute to maintain the trend, and it is likely it will also boost LFP in the 65-69 age group. On the other hand, in 2014 an early retirement option at age 63 without actuarial adjustment was re-introduced for those with 45 contribution years, which could partially offset the effect of previous efforts towards more sustainability. In addition, current attempts to make retirement more "flexible" - but without increasing the benefit adjustments to retirement age to an actuarial level - may backfire and precipitate earlier retirement (Börsch-Supan, A., BucherKoenen, T., Kluth, S., Haupt, M., \& Goll, N., 2015).

\footnotetext{
${ }^{5}$ Börsch-Supan, A. H., Coppola, M., \& Reil-Held, A. (2012). "Riester pensions in Germany: design, dynamics, targeting success and crowding-in”.

${ }^{6}$ See Börsch-Supan, Axel H., and Christina B. Wilke. (2006) "The German public pension system: How it will become an NDC system look-alike".
} 


\section{Historical trends of LFP determinants}

\subsection{Health}

Health improvement and increased longevity seem natural candidates that could help explaining LFP of older workers, and also for this reason health and disabilities have been extensively studied in previous works of this series. Here we will concentrate in particular on common trends, if any, in the evolution of health and LFP.

As a first step, we will document trends in mortality. The implicit assumption here is that a declining mortality reflects health improvements also at earlier ages which, in turn, should predict higher ability to work. Figure 12 shows cohort mortality rates at age 60 by gender since 1960. It depicts a clear downward trend: during the last five decades, mortality rate has halved for both men and women. However, mortality of men was around two times that of women in 1960, so longevity of men is getting closer to that of women.

Figures 13 and 14 show one-year mortality rates for men and women in 1960, 1985 and 2010. Mortality rates are on a logarithmic scale, so the linear increase depicted actually represents an exponential increase in mortality rates by age. These figures tell us that mortality rates of women are lower than mortality rates of men at all ages, and that mortality rates have sizably decreased since 1960, without showing signs of deceleration. Actually, for men the increase in longevity in the last 25 years has been higher than for women. A man in 1960 had a 5\% probability of dying within the next year at age 69, while the same probability was reached at age 71 in 1985 and at age 77 in 2010. The respective ages for women are 73, 77 and 81.

Figures 15 and 16 depict the relative improvements in longevity by age for men and women, expressed as the ratio of mortality rates between 1985 and 1960, and between 2010 and 1985 (thus smaller numbers indicate larger improvements). These figures clearly show that the increase in longevity of men between 1985 and 2010 was two times larger than between 1960 and 1985, while for women the increase was constant. The relative gain between 1985 and 2010 is thus higher for men than for women. The biggest relative gain in longevity for men was registered between ages 55 and 70 in the period 1960-1985 and at later ages (65-80) in the period 1985-2010. For women, on the contrary, the biggest relative improvements have been at around the same ages (65 to 80). 
These findings are interesting when put in relation to LFP trends. Before the mid-80s, when the relative longevity improvements of men were particularly strong for ages at risk of retirement, the LFP of this same age group was in a decreasing trajectory. When the trend reversed, it did so especially for the 60-64 age group, while remaining pretty stable for those older than 65 despite the fact that longevity was rising especially in this group. As regards women, the biggest relative improvements have mainly affected women older than 65; however this is the only age group among women where LFP has remained pretty stable throughout the years.

As longevity improvements are not a perfect measure of health, we conclude this subsection showing some evidence on self-assessed health in Germany from GSOEP. We argue, however, that self-assessed health may not be a good measure of secular trends in health either. If individuals evaluate their health using as reference a contemporaneous average healthy individual, it is possible that no trend at all is captured by self-assessed health, even if objective average health actually improved through time.

GSOEP has collected data on satisfaction with health annually since the first wave in 1984. Health satisfaction is measured on a 0-to10 scale, and we define as "fair-poor health" satisfaction below or equal to 5. Data on self-rated health are instead available only since 1992. In this case, "fairpoor” is defined as rating one's health as bad, poor or satisfactory. Trends for these two variables are presented in Figures 17 and 18, separately by gender and age group. First of all, it is clear that data are pretty volatile, another reason why they should be interpreted with caution. In general, however, a downward trend in fair-poor health is present for both variables and in all categories considered. The trend is decreasing faster in the category of individuals older than 65. In this respect, the trends are compatible with the secular increase in life expectancy illustrated above.

In conclusion, although it is certainly plausible for health to be an important determinant of the level of LFP, it seems unlikely that it may have been the cause of the sudden trend reversal registered in the 90s.

\subsection{Education}

Educational attainment is another crucial determinant of LFP, and increases in education can be expected to increase the ability, the willingness and the opportunities to work at older ages. First of all, those with higher education start their career later and may thus need to work at older ages 
in order to reach certain eligibility requirements or benefit levels. Besides, education may be seen as an investment - better educated workers are generally also paid more - which provides incentives to remain employed. Those with higher education are also less likely to become unemployed or discouraged. Finally, there is likely a positive relation between education and health at older ages and a negative relation between education and being employed in physically demanding jobs. In fact, those with a college degree are much more likely to be in the labor force at older ages: in the 2013 GSOEP sample, around $40 \%$ of men and $43 \%$ of women older than 55 holding a postsecondary diploma were in the labor force. The respective numbers for those without high-school diploma were $28 \%$ and $16 \%$.

Figures 19 and 20 show the trends in upper secondary (high-school) and post-secondary (college) attainment by gender and age group. A few interesting facts can be observed. First of all, for both genders and in all age groups, the proportion of individuals with high-school or college has been increasing. The increasing trend of women with high-school is much faster than for men, so much that the gender gap has almost disappeared in the younger cohort (55-59). The increase in college attainment is instead similar to that of men, but the gender gap is still present in all the cohorts considered.

As regards men, the steepest increase is registered for college attainment. It is interesting to notice, however, that the educational gap among different cohorts is closing. In fact, even among primeage men (40-44 years, which we do not show in the graphs) slightly more than one third of individuals nowadays own a college degree. It is thus likely that future gains in educational attainment will slow down. As increasing educational attainment has most likely played an important part in the LFP increase of older men, it is also possible that education will not anymore be a crucial determinant of LFP trends in the future.

\subsection{Labor market factors: occupation, real wages and unemployment}

Labor demand factors may be important drivers of older individuals' LFP as well, but they are often overlooked in the literature. In this section, we will in particular discuss the trends in the composition of employment, real wages and unemployment.

Figures 21 and 22 show the trend in unemployment for men and women, separately for all workers and for older workers only. This graphs are remarkable because they track a set of important events 
in economic history. The first two peaks, around 1975 and 1983, may be explained by the two oil crisis of 1973 and 1979. After that, instead of going back to pre-crisis levels, unemployment remained high, showing a pattern characterized by a hysteresis problem. It hit a high in 2005, and finally started decreasing after that date, probably caused by the incisive "Agenda 2010" labor market reforms in Germany.

If we look at the unemployment of older workers, we can recognize at least a few instances where unemployment of older workers diverge from general unemployment, likely due to new public pension and labor market regulations that affected only these workers, see Börsch-Supan and Schnabel (2010). Specifically, during the 80s the two lines go in opposite directions and even cross. While unemployment in the population was decreasing, unemployment of older workers was increasing due to the "bridge to retirement" we discussed in the Section 3: more generous unemployment benefits induced more and more workers to use unemployment insurance as an early retirement pathway. This created a wedge between unemployment of older and younger workers which started to decrease only after 1997, when actuarial adjustments for early retirement started to phase in. It thus seems that unemployment of older workers in Germany has been indirectly affecting LFP of older workers through the effect of public pension and labor market regulations, rather than be itself a cause of early labor market exit.

Another factor to analyze is real wages growth. This is interesting also in light of the increase in education that we illustrated in the previous subsection: as the workforce became more educated, and thus also more productive, we should expect to see this reflected in higher compensations, both in absolute terms and relative to younger workers, for which increases in education are not anymore as fast as for older cohorts (see Burtless, 2013). GSOEP has been asking respondents how much did they earn from their work last month (both gross and net of taxes and social contributions to public pensions, unemployment and health insurance) since 1984. Gross and net yearly income, instead, are only available from 1990 and 2000 respectively, so here we will only show monthly earnings, expressed in 2010 euro.

In Figure 23 we show the evolution of median gross wages for older workers by gender. We only include full-time workers to take into account the fact that older workers may disproportionately hold part-time jobs. Gross wages have been clearly increasing for both men and women, even if growth seems to have slowed down and even reversed, especially for men, during the 2000s. This 
trend, however, characterises wages of all workers in Germany, as documented in Brenke (2009). The author shows that net real wages in Germany have hardly risen, and even declined between 2004 and 2008, not due to higher taxes or social-security contributions but rather due to very slow wage growth.

This slow growth has happened despite the increase in workers' educational attainments and the shift towards more qualified jobs. The latter is documented in Figure 24, where we show the distribution of occupations by gender in the first and last available years of GSOEP. It is possible to notice that professions which require higher qualification have been growing in importance at the expense of professions based on manual labor or simple non-manual activities. This shift towards less physically demanding jobs ${ }^{7}$ may itself contribute explaining later retirement.

Despite the slowing down of wage growth, we still expect the relative educational gain of older workers to be reflected in higher compensations relative to younger workers. Thus, in Figure 25 we show the median monthly wage of workers aged 55 to 69 as a percent of the median wage of prime-age (25-54) workers. In fact, median wages of older workers tended to increase in the period

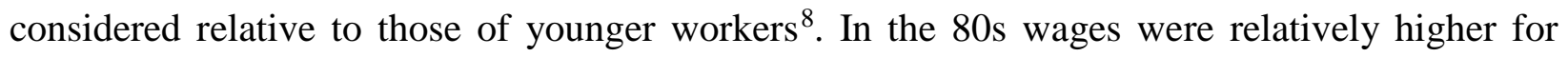
prime-age workers, but in the early and late 90s, for men and women respectively, the situation reversed.

\subsection{Spouse's LFP}

Another argument that has been put forward in the retirement literature is that one's spouse's LFP might be important for individuals' retirement decisions. There are two main potential explanations of why this might be true, which operate in opposite directions (see Schirle, 2008). First of all, the extra family income earned by a working spouse allows the other spouse to enjoy more leisure (income effect), thus reducing her/his probability of being in the labor force. Second, if couples have a preference for shared leisure time, we can expect joint retirement decision, which means higher probability of being in the labor force as long as the spouse is in the labor force too.

To shed some light on this issue, we show in Figure 26 the LFP trends of 60-64 years old men and women by marital status. We can notice that the U-shape that we documented above for men seems

\footnotetext{
${ }^{7}$ Cognitive ageing, on the other hand, may represent a problem especially for those with higher education.

${ }^{8}$ As noticed by Burtless (2013), wages are only observed for workers. As low earners tend to leave the workforce earlier than high earners, observed median wages are higher than potential wages of all older individuals.
} 
to be driven by married man, as before the 2000s the trend for single men looks quite different and somehow erratic. After the actuarial adjustments started to phase in, however, the trends for single

and married men look very similar, increasing the suspicion that public pension rules may have had a crucial role in shaping the trend. Nevertheless, the strong increase in LFP of married women and the similar trends in LFP for married men and women may suggest that men in particular could have responded to the increase of their wives’ LFP by postponing their exit from the labor market.

\section{Decomposition Analysis}

In this section, we propose a decomposition analysis of labor force participation in order to assess how much of the changes in LFP can be attributed to the three main factors presented above: education, health and spouse's labor force participation. The original decomposition method was proposed by Oaxaca (1973) and Blinder (1973) and it consisted in decomposing changes (e.g., through time) or differences (e.g., between groups) in the mean of an outcome variable in a component that reflects differences in the distribution of (observed and unobserved) characteristics and a component which reflects different returns to (observable and unobservable) characteristics. Since then, the literature on decomposition has expanded considerably; the main development consisted in going beyond the mean by extending the decomposition to other distributional parameters.

An important distinction exists between "aggregate” and "detailed” decompositions. In the former, the overall difference in outcomes between two groups is only divided into its two components: the "explained" one (attributable to differences in characteristics) and the "unexplained" one (attributable to different returns to characteristics). The "detailed" decomposition, which we employ in our analysis, allows instead to look at the contribution to the overall difference of each individual covariate. Specifically, the detailed decomposition can apportion the explained and the unexplained effects into components attributable to each explanatory variable (see Fortin et al., 2011).

In the following, we will follow the decomposition strategy used by Schirle (2008): this is similar to the method developed by DiNardo et al. (1996), but extended to the case of a binary outcome variable such as labor force participation. As we will consider many variables in our decomposition, the analytical description of the method is simplified by using a set of only two 
generic variables. Very broadly, this semi-parametric method consists in fixing a baseline year ( $s=1984$, in our case) and creating for any subsequent year $t$ counterfactuals of the participation rate, had each factor remained as in year $s$. If we repeat this exercise for every year up until 2013, we can get an estimate of how the evolution of LFP would have been over this entire period if the distribution of certain factors had remained constant after 1984.

The creation of the counterfactual is based on a reweighting function which captures the differences in the distribution of a certain explanatory variable between two periods. The decomposition proceeds by sequentially adjusting for each factor, introducing one covariate on top of those which have already been adjusted for. One well-known shortcoming of this approach is that the result depends on the order in which the variables are introduced. For this reason, we will check the robustness of our result by reversing the order of decomposition.

The decomposition starts by defining the probability to participate in the labor force $L$ in $t$, which may be written as:

$$
\begin{aligned}
P_{t}(L=1)= & \sum \sum P_{t}\left(L=1, X_{1}=x_{1}, X_{2}=x_{2}\right) \\
& =\sum \sum P_{t}\left(L=1 \mid X_{1}=x_{1}, X_{2}=x_{2}\right) \times P_{t}\left(X_{1}=x_{1} \mid X_{2}=x_{2}\right) \times P_{t}\left(X_{2}=x_{2}\right)
\end{aligned}
$$

where $\mathrm{X}_{1}$ and $\mathrm{X}_{2}$ represent two generic explanatory factors we are interested in and the summation is over the support of $\mathrm{X}_{1}$ and $\mathrm{X}_{2}$. In the first stage of the decomposition, we want to create a counterfactual probability representing what the participation decision would have been in $t$, had the distribution of $\mathrm{X}_{1}$ stayed the same as in $s$ :

$$
\begin{aligned}
P_{C 1 t}(L=1)= & \sum \sum P_{t}\left(L=1 \mid X_{1}=x_{1}, X_{2}=x_{2}\right) \times P_{s}\left(X_{1}=x_{1} \mid X_{2}=x_{2}\right) \times P_{t}\left(X_{2}=x_{2}\right) \\
& =\sum \sum P_{t}\left(L=1 \mid X_{1}=x_{1}, X_{2}=x_{2}\right) \times \psi_{X^{1} \mid X^{2}} P_{t}\left(X_{1}=x_{1} \mid X_{2}=x_{2}\right) \\
& \times P_{t}\left(X_{2}=x_{2}\right)
\end{aligned}
$$

where $\psi_{X^{1} \mid X^{2}}$ is a reweighting function that, using Bayes' rule, can be rewritten as:

$$
\psi_{X_{1} \mid X_{2}}=\frac{P\left(X_{1}=x_{1} \mid X_{2}=x_{2}, T=s\right)}{P\left(X_{1}=x_{1} \mid X_{2}=x_{2}, T=t\right)}=\frac{P\left(T=s \mid X_{1}=x_{1}, X_{2}=x_{2}\right) / P\left(T=s \mid X_{2}=x_{2}\right)}{P\left(T=t \mid X_{1}=x_{1}, X_{2}=x_{2}\right) / P\left(T=t \mid X_{2}=x_{2}\right)}
$$


This transformation reduces a high dimensional object into a one-dimensional object that can be estimated by pooling observation of year $t$ and $s$ and running a probit model ${ }^{9}$ where the dependent variable indicates whether the observation belongs to year $t$ or to year $s$.

Similarly, we will then obtain a second counterfactual which also accounts for changes through time in $\mathrm{X}_{2}$. Notice that this time the counterfactual tells what the participation decision would have been in $t$, had the distribution of $\mathrm{X}_{2}$ and $\mathrm{X}_{1}$ stayed the same as in $s$ :

$$
\begin{aligned}
P_{C 2 t}(L=1)= & \sum \sum P_{t}\left(L=1 \mid X_{1}=x_{1}, X_{2}=x_{2}\right) \times \psi_{X_{1} \mid X_{2}} P_{t}\left(X_{1}=x_{1} \mid X_{2}=x_{2}\right) \\
& \times \psi_{X_{2}} P_{t}\left(X_{2}=x_{2}\right)
\end{aligned}
$$

where the new reweighting function:

$$
\psi_{X_{2}}=\frac{P\left(X_{2}=x_{2} \mid T=s\right)}{P\left(X_{2}=x_{2} \mid T=t\right)}=\frac{P\left(T=s \mid X_{2}=x_{2}\right) / P(T=s)}{P\left(T=t \mid X_{2}=x_{2}\right) / P(T=t)}
$$

can again be estimated as indicated above ${ }^{10}$.

The illustrated procedure can of course be extended to any number of explanatory variables. Here we concentrate on the factors that, in light of previous discussion, we deem important for explaining LFP in Germany: education, health and spouse's labor force participation. The decomposition will be repeated for each $t \in[1985,2013]$, keeping $s=1984$ as the baseline year. As a first step, we need to estimate a pooled probit model of labor force participation using GSOEP data from 1984 to $2013^{11}$. The model includes year and age dummies, education dummies, indicators for marital status, spouse's employment status, fair-poor health and a quadratic in experience. We estimate this model using sample weights, separately for men and women. The reweighting functions include similar controls and, after having estimated their predicted values,

\footnotetext{
${ }^{9}$ The Di Nardo, Fortin and Lemieux (1996) method is indeed "semi-parametric", because of the parametric reweighting approach.

${ }^{10}$ Notice that in the case of a binary variable the reweighting function is:

$\psi_{X_{2}}=\frac{P\left(X_{2}=x_{2} \mid T=s\right)}{P\left(X_{2}=x_{2} \mid T=t\right)}=\left\{\begin{array}{l}\frac{P_{S}\left(X_{2}=1\right)}{P_{t}\left(X_{2}=1\right)} \text { if } X_{2}=1 \\ \frac{P_{S}\left(X_{2}=0\right)}{P_{t}\left(X_{2}=0\right)} \text { if } X_{2}=0\end{array}\right.$

${ }^{11}$ By running a pooled model, we are implicitly assuming that the parameters describing LFP decision do not vary through time. This assumption could be relaxed by running separate regressions for each year.
} 
they are multiplied by the original sample weights in order to obtain the counterfactual participation rates.

Figure 27 shows the counterfactual labor force participation of men in the 55-64 age group for the period 1984-2013. The graph shows that the effect of education, health and spouse's labor force status seems to have increased up until the end of the 90s and to have remained more stable after that date. If those characteristics had not changed after 1984, LFP in 2000 would have been around 5 percentage points lower than what observed. The effect on health alone seems not to be substantial, while the remaining wedge seems to be similarly driven by increases in education and in spouse's LFP. What is striking, however, is that these variables do not explain at all the fast increase in LFP registered after 2000: the difference between actual and counterfactual LFP in 2013 is still around 5 percentage points, as in 2000.

The picture for women looks even less suggestive for the hypothesis that education, health or spouse's employment are the main drivers of their strongly increasing labor force participation. This can be seen from Figure 28. In this case, the three factors seem to explain very little of the fast and constant increase in females LFP. Besides, up until the end of the 1990s, basically no effect is visible. After that date, education drives the wedge between actual and counterfactual LFP. However, the effect of education seems smaller than expected in light of the steep increase in education of women illustrated above.

These negative findings are robust against reversing the order of the explanatory variables. The path dependency is basically an omitted variables problem (see Fortin et al., 2011), originated by the sequential introduction of covariates in the decomposition, so diverging results should be expected unless the effect of our factors of interest is uncorrelated with the excluded covariates. In order to check the robustness of the counterfactual analysis to the problem of path dependence, we also perform a reverse order decomposition.

As shown in Figures 29 and 30, for both men and women, the reverse decomposition has the effect of slightly increasing the overall gap between actual and counterfactual trends. Particularly the effect attributed to education seems to become bigger. However, these small differences do not change our previous conclusions. 


\section{Conclusions}

Labor force participation of older men in Germany has experienced a remarkable reversal around the late 1990s. After a long declining trend that began in the early 1970s, LFP for older men has strongly increased again. This increase has lasted until today. In contrast, labor force participation of older women in Germany has not experienced such an U-shaped pattern but has steadily increased since the 1970s. This paper documents these trends and some potential drivers that have been mentioned in the literature, and then uses a decomposition analysis to find out whether the three most prominent drivers - education, health and spouse's employment - explain these trends.

Our answer is no. Regarding men's labor force participation, all three variables have a significant influence but they do not explain the U-shaped reversal. Future work will therefore focus on the role of public pension rules in explaining the trend reversal among older men's labor force participation.

Regarding women's labor force participation, the three variables do not even have an economically substantive effect. Whether public pension rules play a role is unclear. Most probably, the secular change of women's role in society is the main driver of the steadily increasing labor force participation among German women. 
Figures

Figure 1 Labor force participation by age group, Men (OECD)

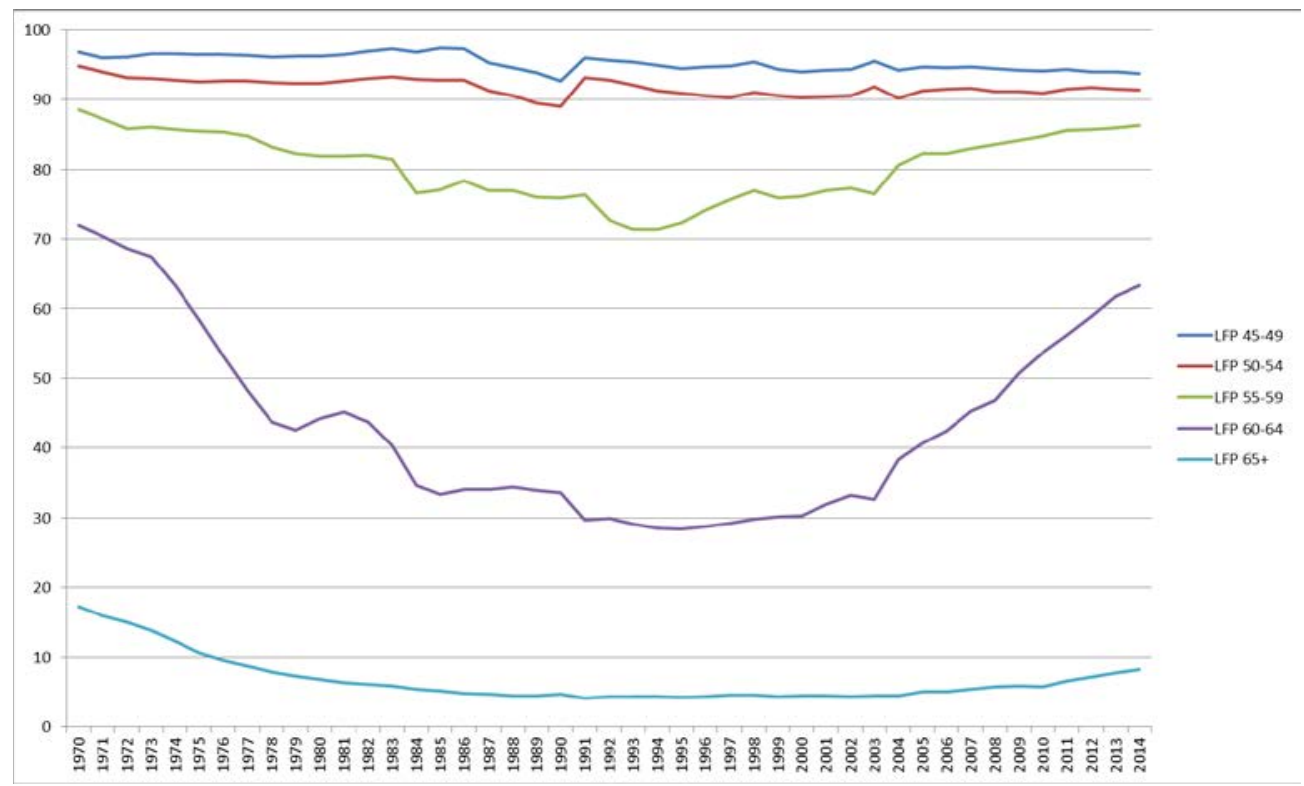

Source: OECD 
Figure 2 Labor force participation by age group, Women (OECD)

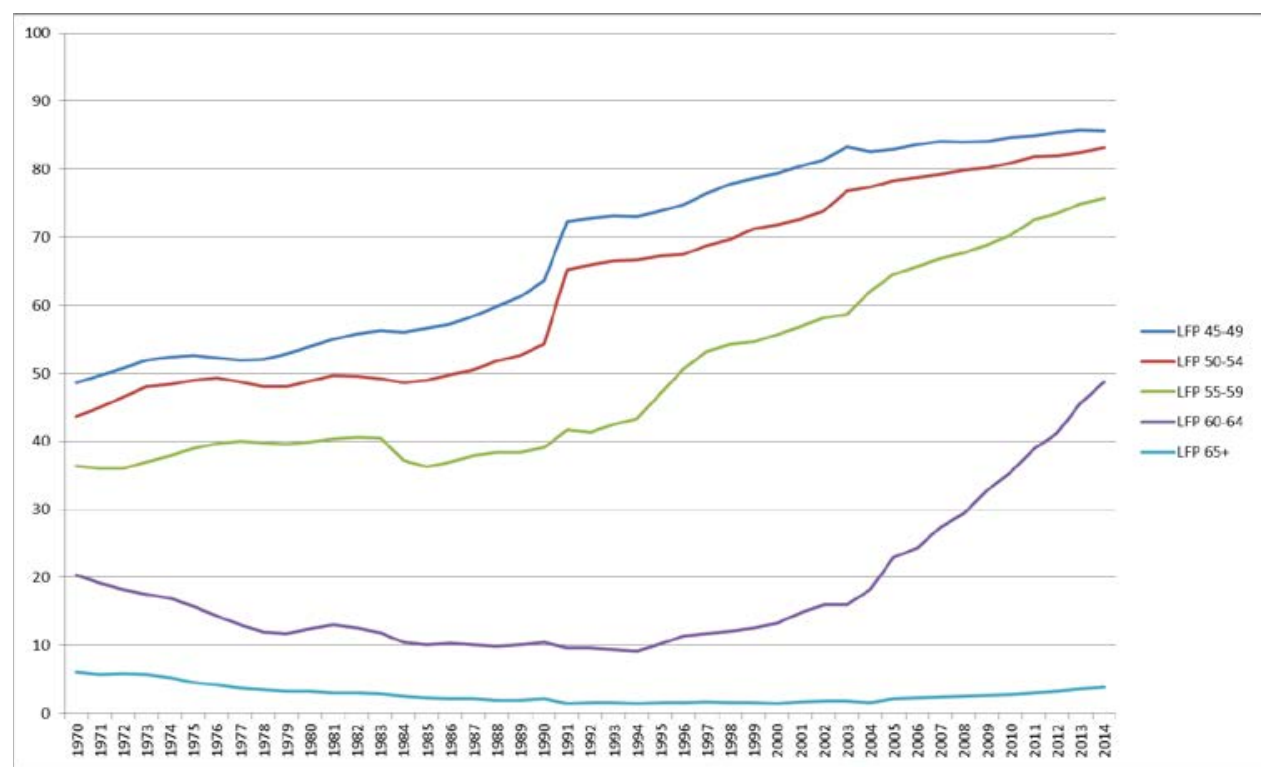

Source: OECD 
Figure 3 Labor force participation rate by age and gender, 1984-2013

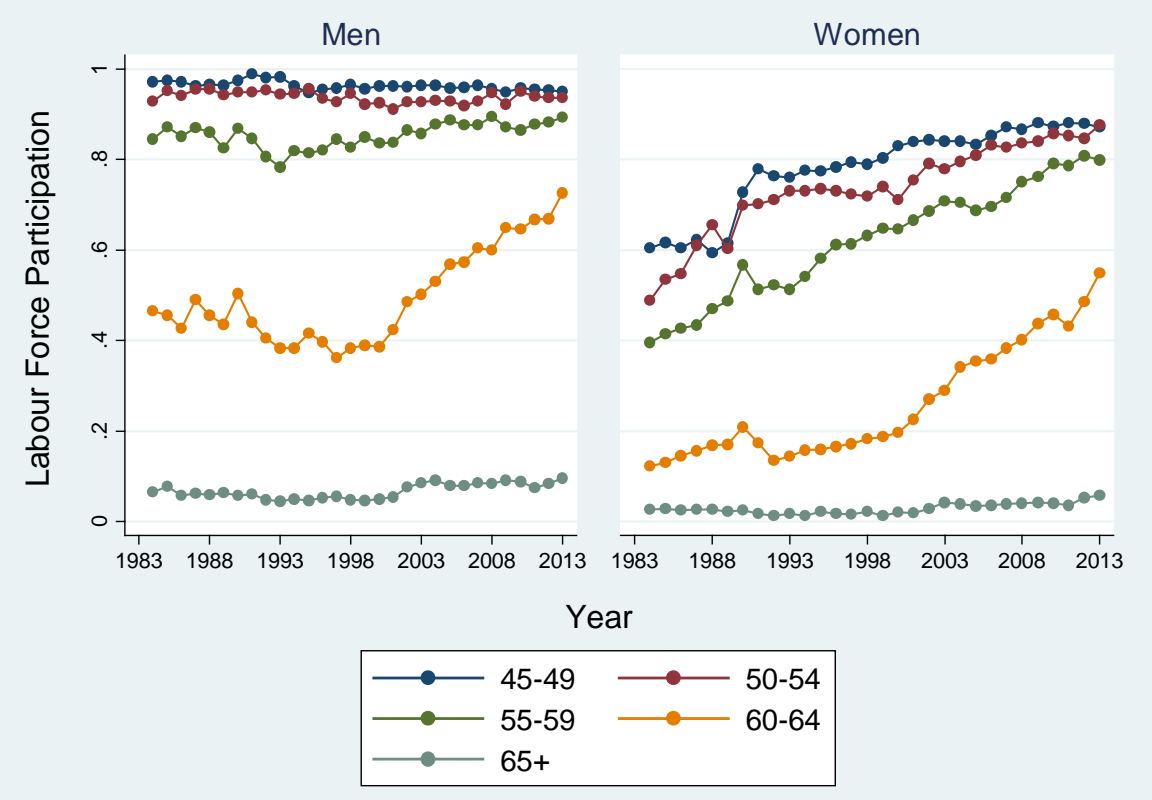

Source: GSOEP 
Figure 4 Labor force participation by cohort and gender

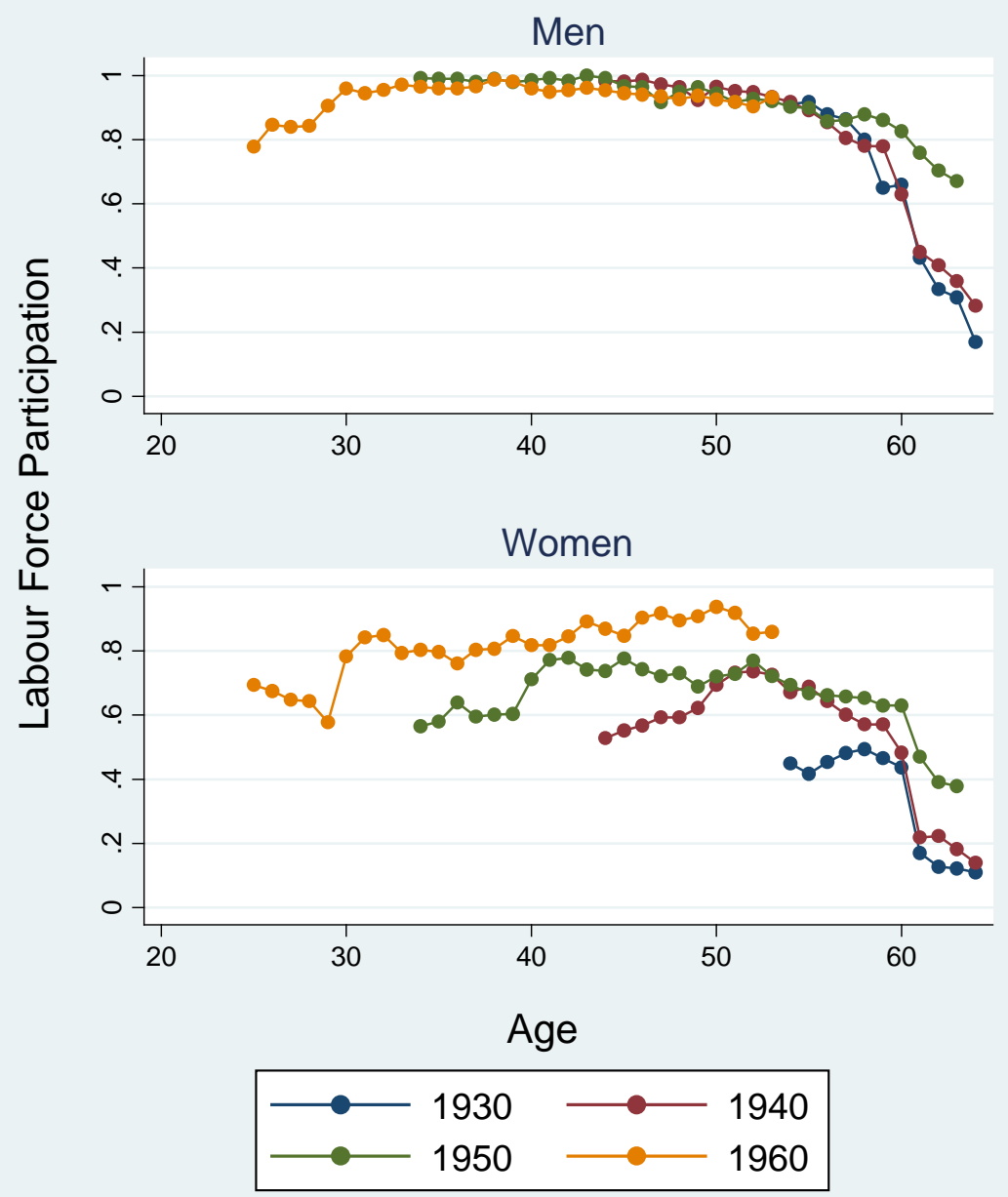

Source: GSOEP 
Figure 5 Labor force participation rates in different years, ages 50-80

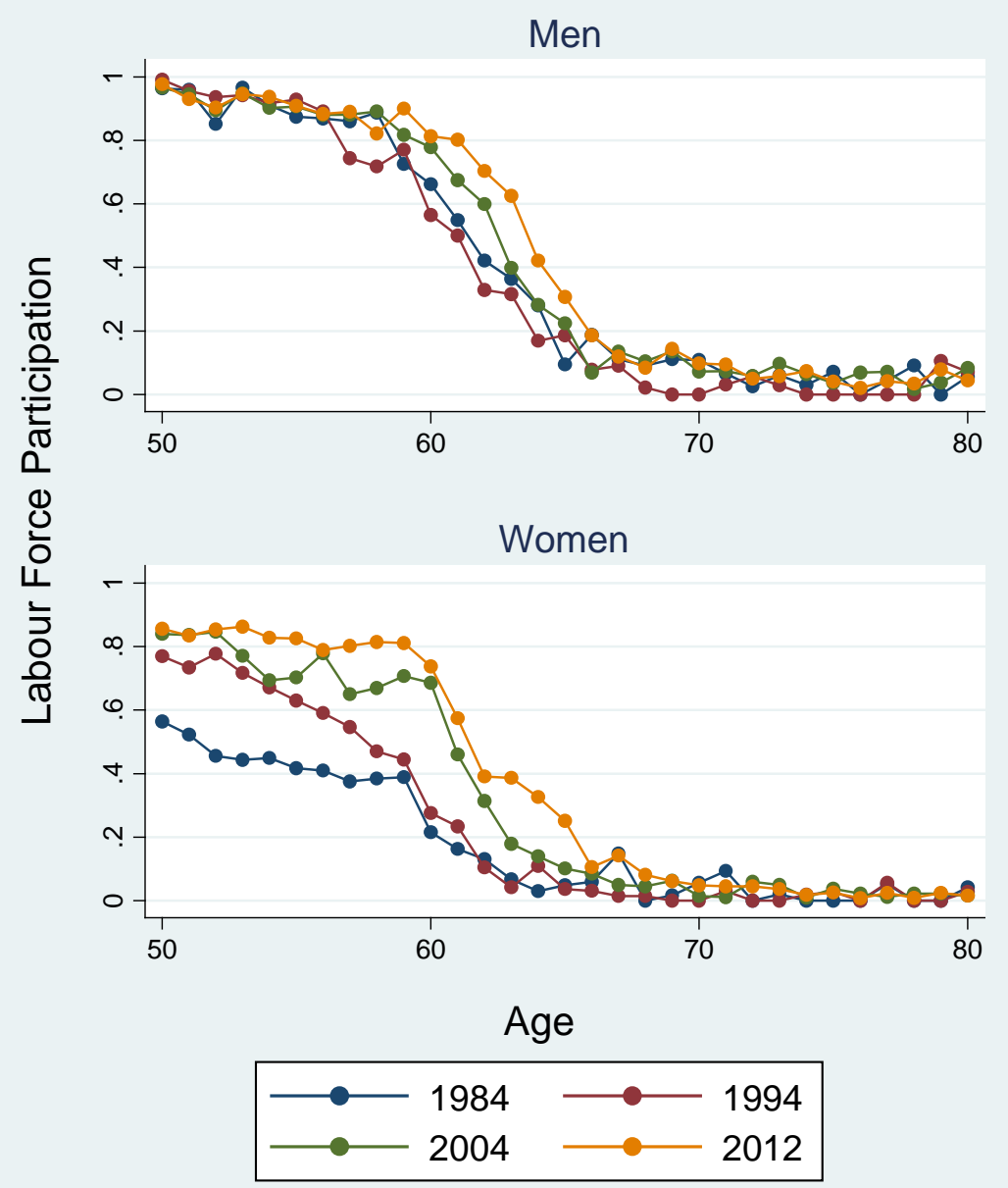

Source: GSOEP 
Figure 6 Labor force participation of men and women in 2012, ages 50-80

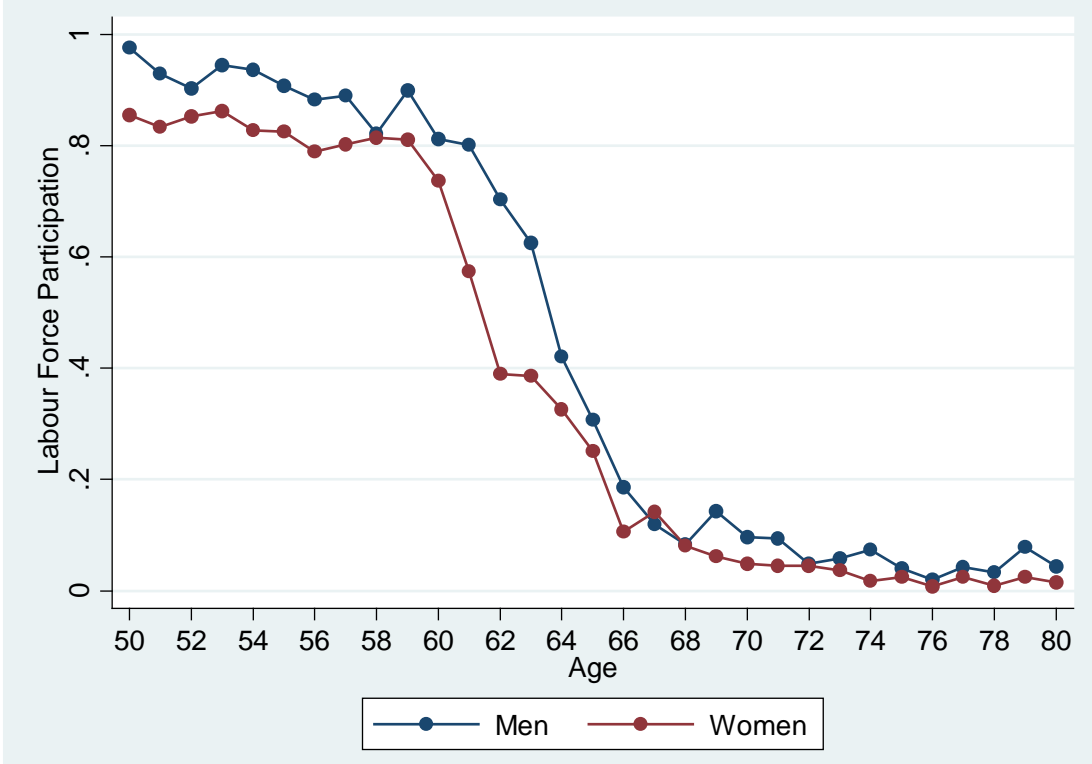

Source: GSOEP 
Figure 7 Pathways to retirement, Men

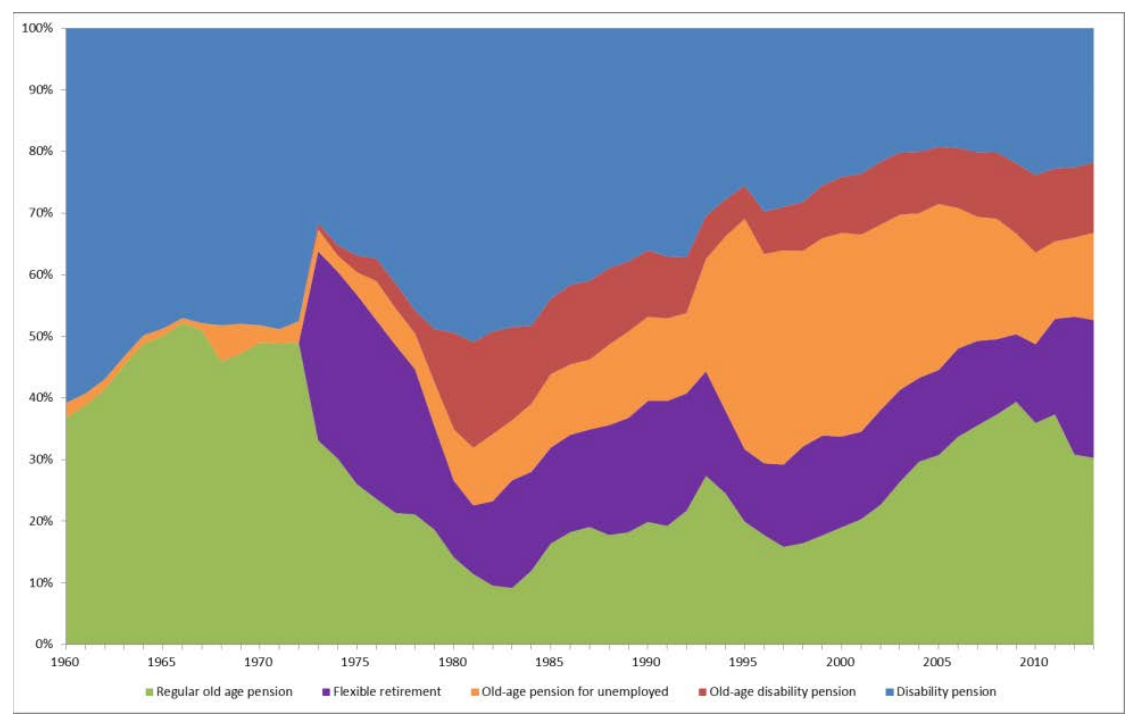

Source: Deutsche Rentenversicherung 
Figure 8 Pathways to retirement, Women

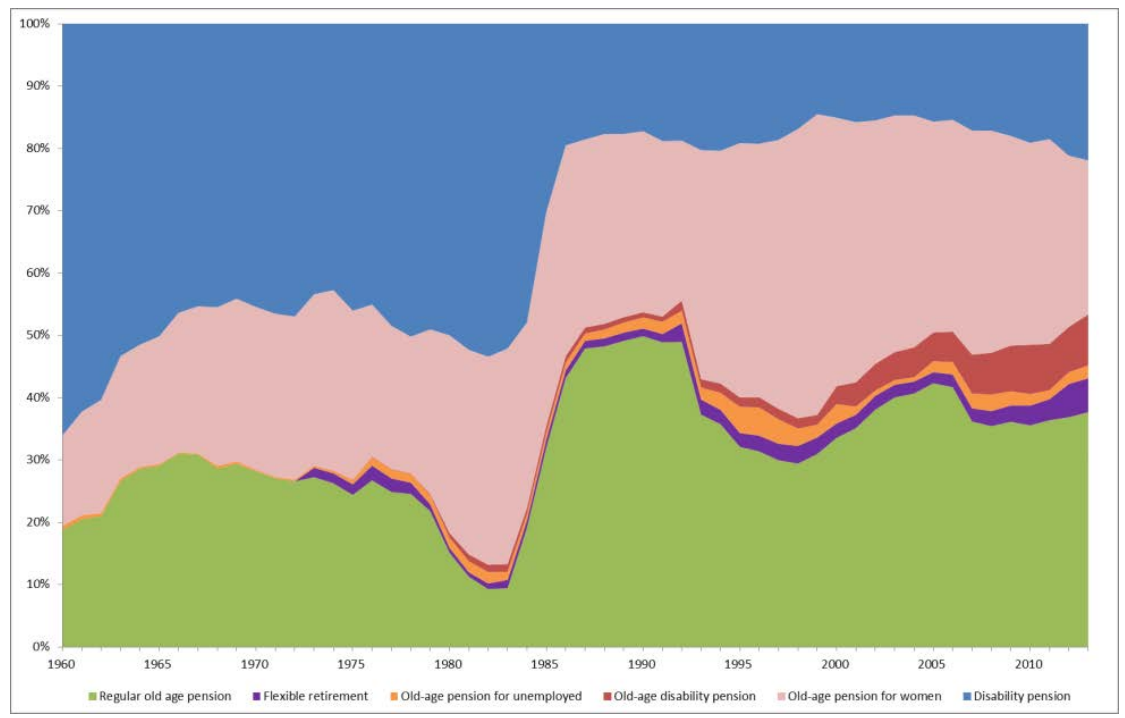

Source: Deutsche Rentenversicherung 
Figure 9 Pension eligibility ages with and without actuarial adjustments

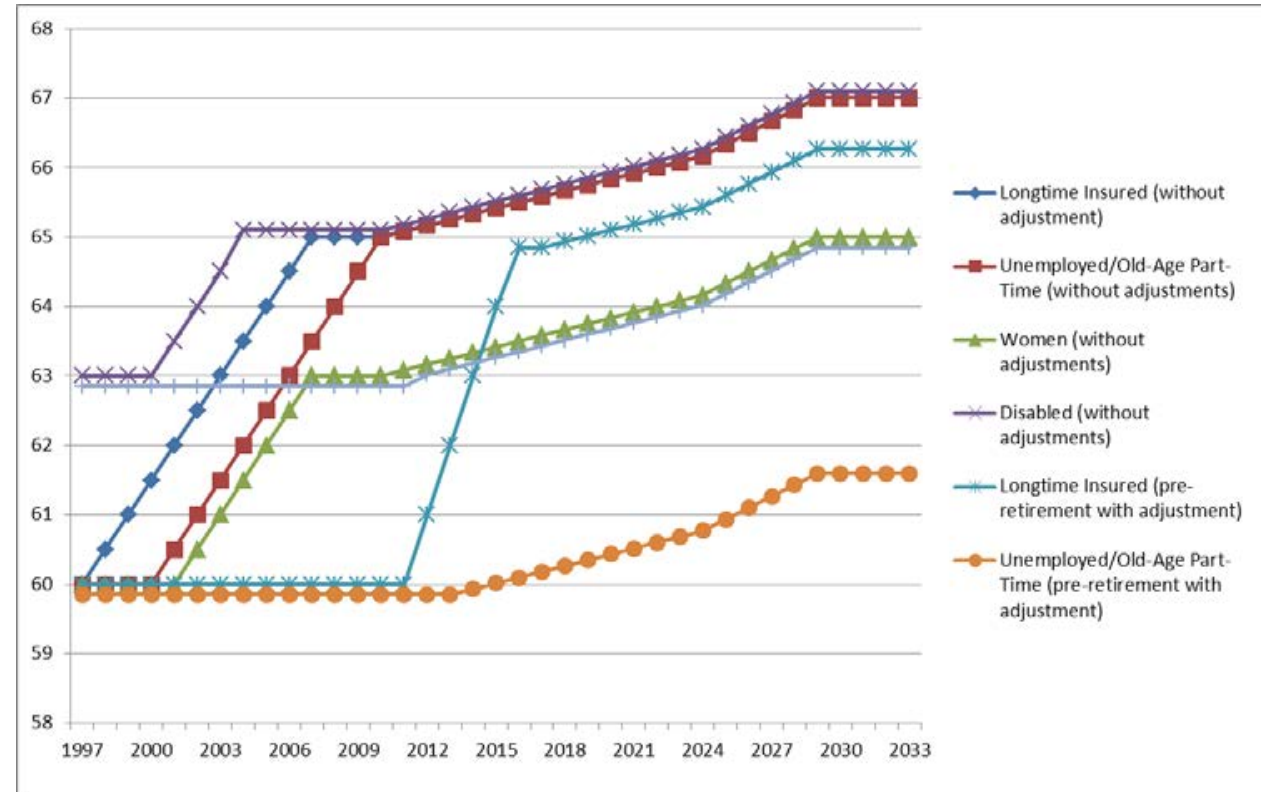


Figure 10 Average retirement age, Men

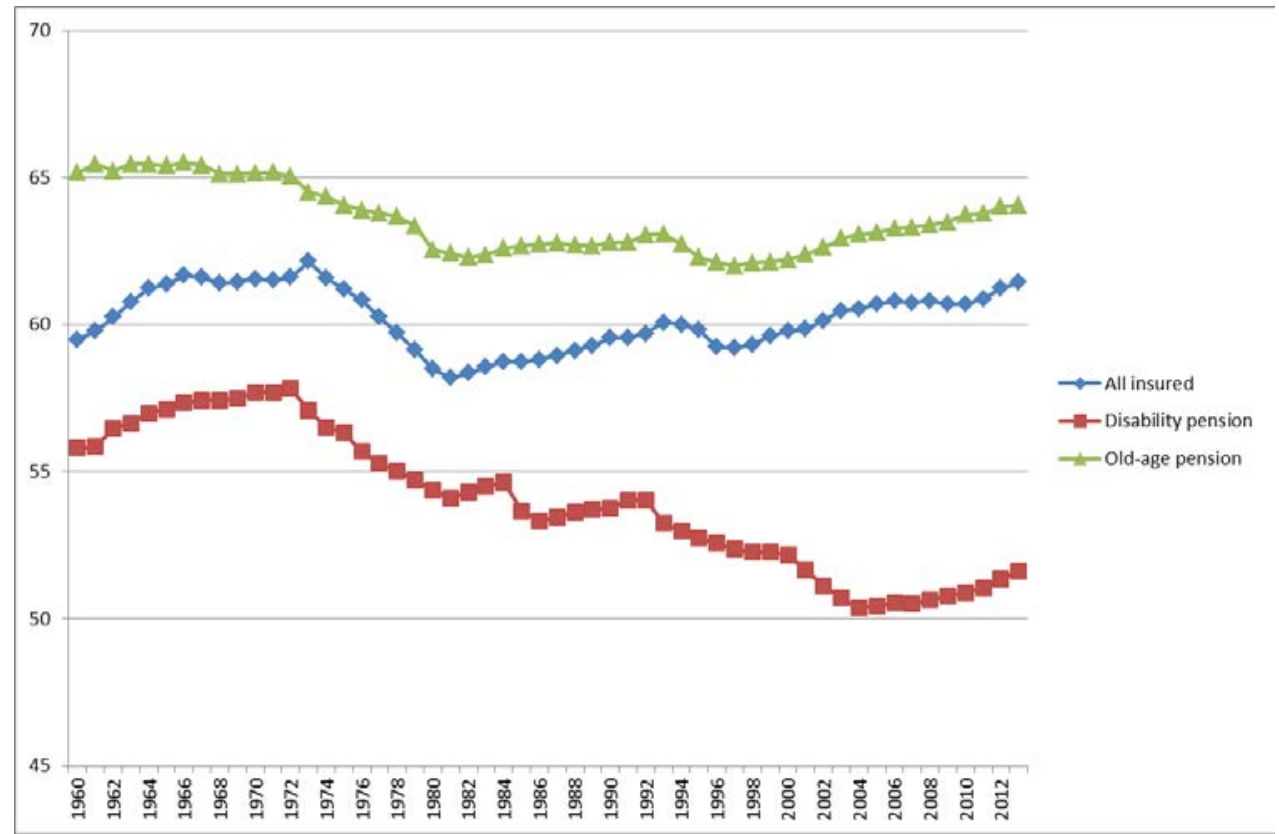

Source: Deutsche Rentenversicherung 
Figure 11 Average retirement age, Women

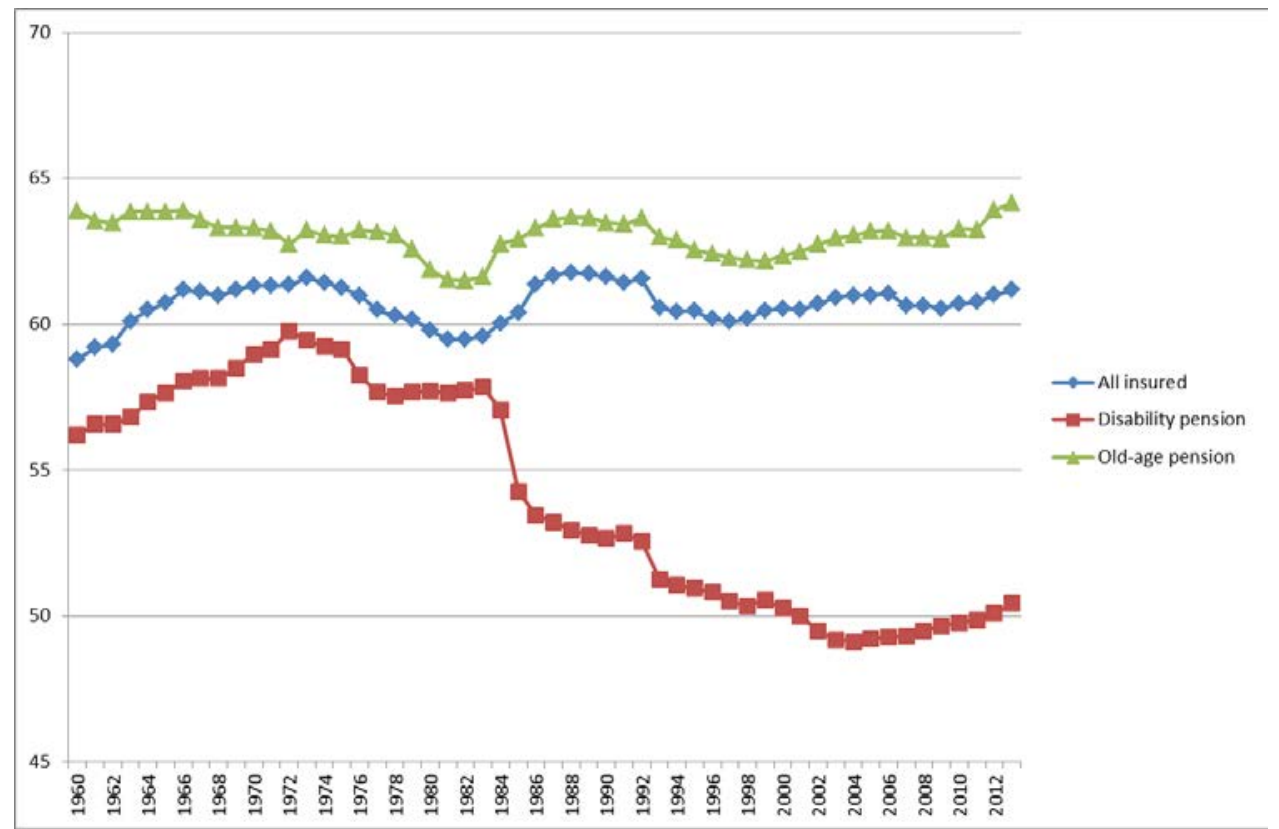

Source: Deutsche Rentenversicherung 
Figure 12 Cohort mortality rates at age 60

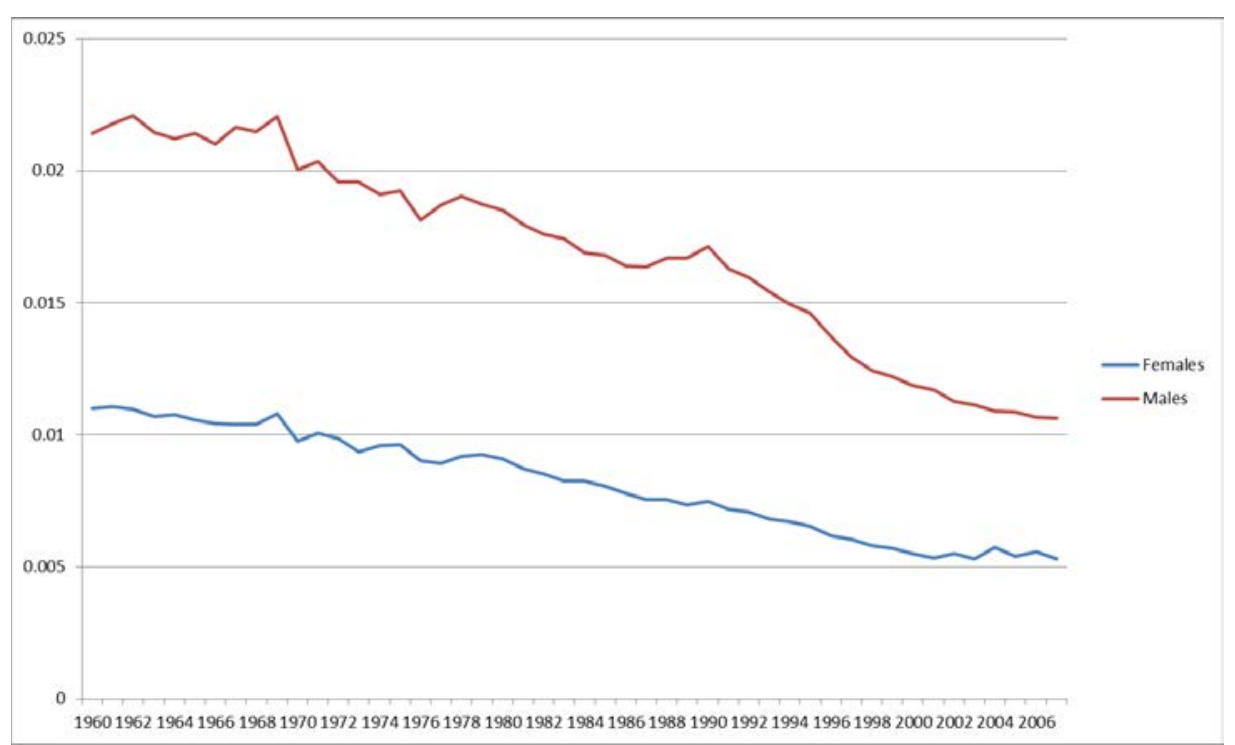

Source: Human Mortality Database 
Figure 13 One-year mortality rate (log-scale) by age, Men (1960, 1985 and 2010)

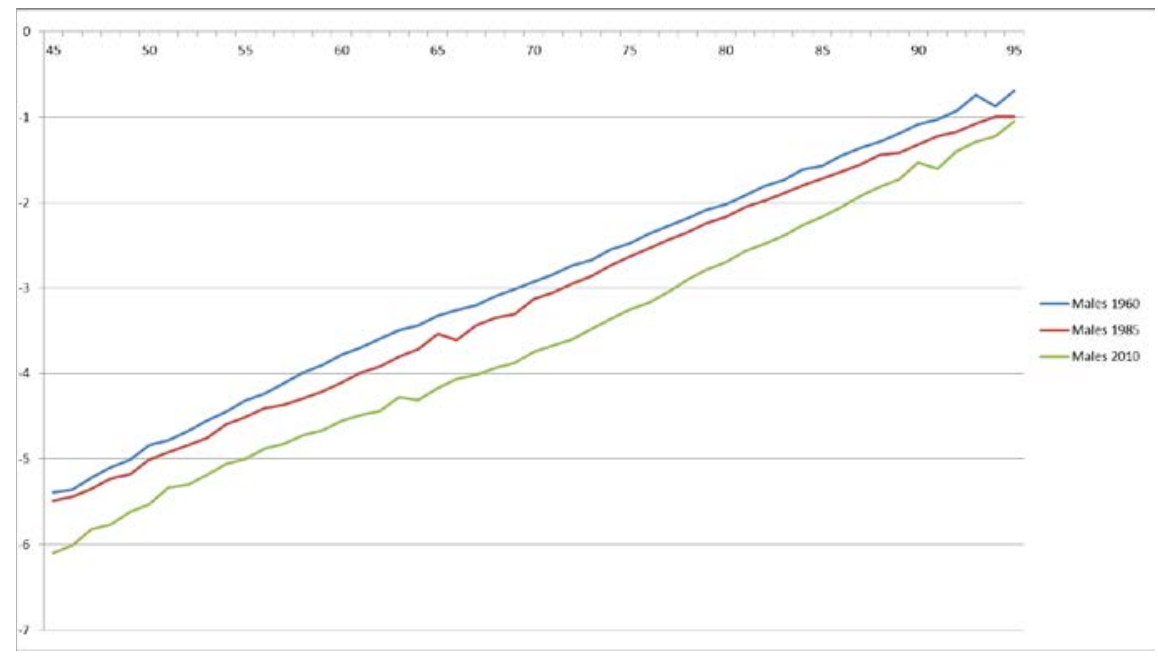

Source: Human Mortality Database 
Figure 14 One-year mortality rate (log-scale) by age, Women (1960, 1985 and 2010)

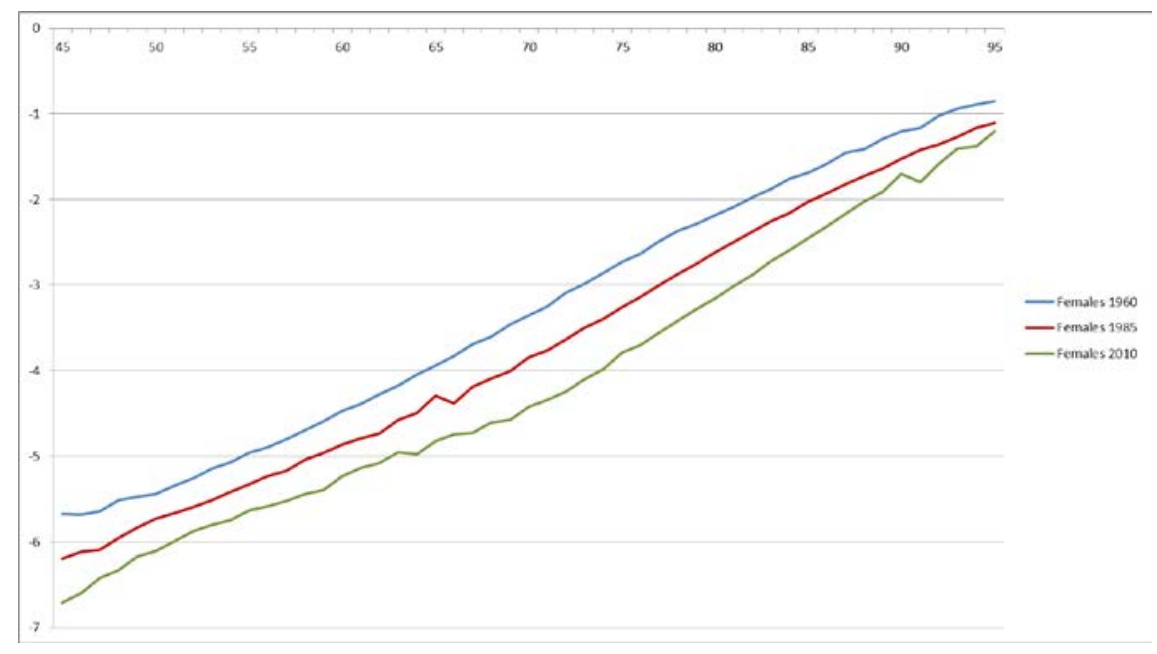

Source: Human Mortality Database 
Figure 15 Ratio of one-year mortality rates, Men

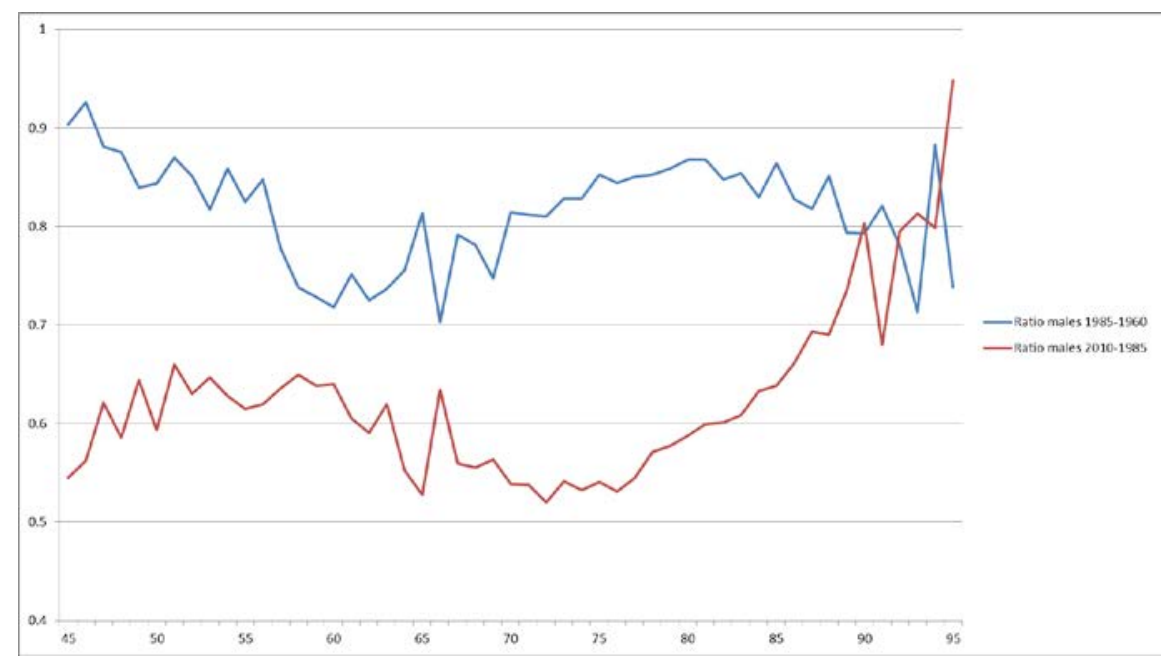

Source: Human Mortality Database 
Figure 16 Ratio of one-year mortality rates, Women

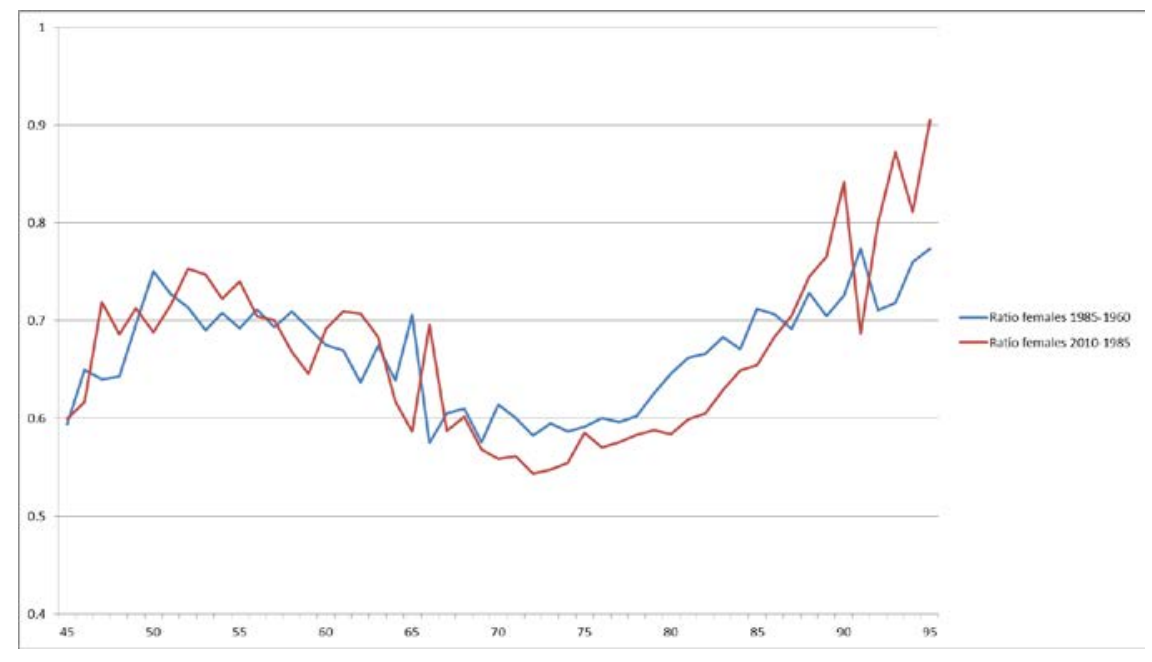

Source: Human Mortality Database 
Figure 17 Health dissatisfaction by sex and age group, 1984-2013

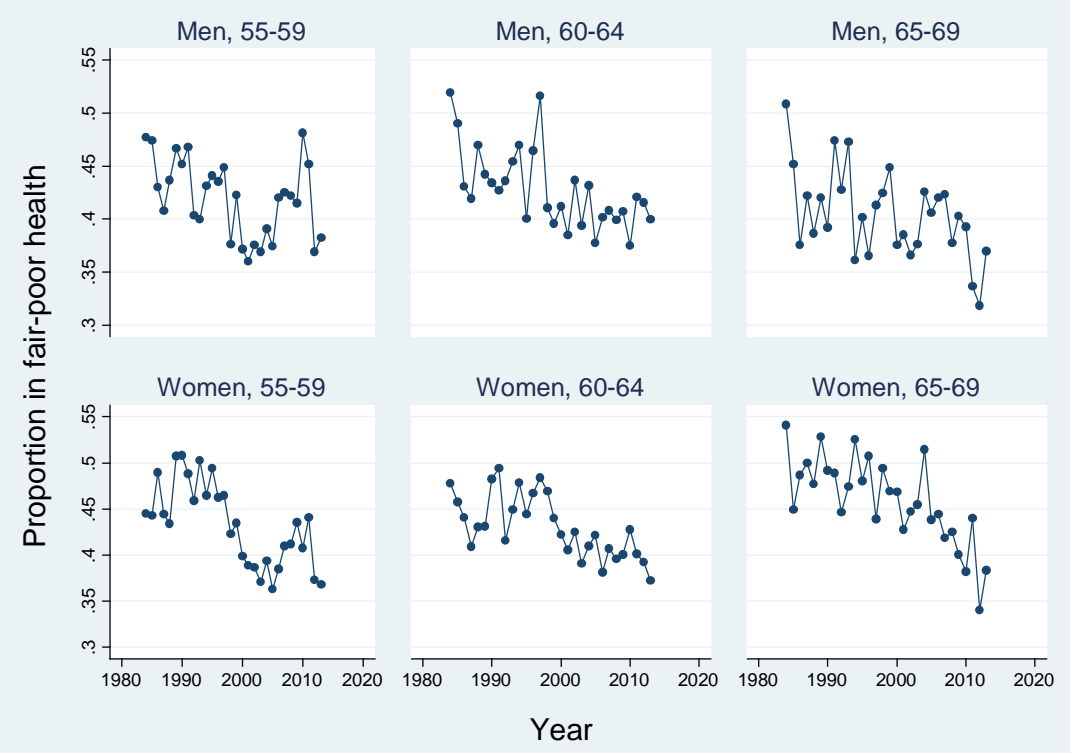

Source: GSOEP 
Figure 18 Self-rated health by sex and age group, 1984-2013

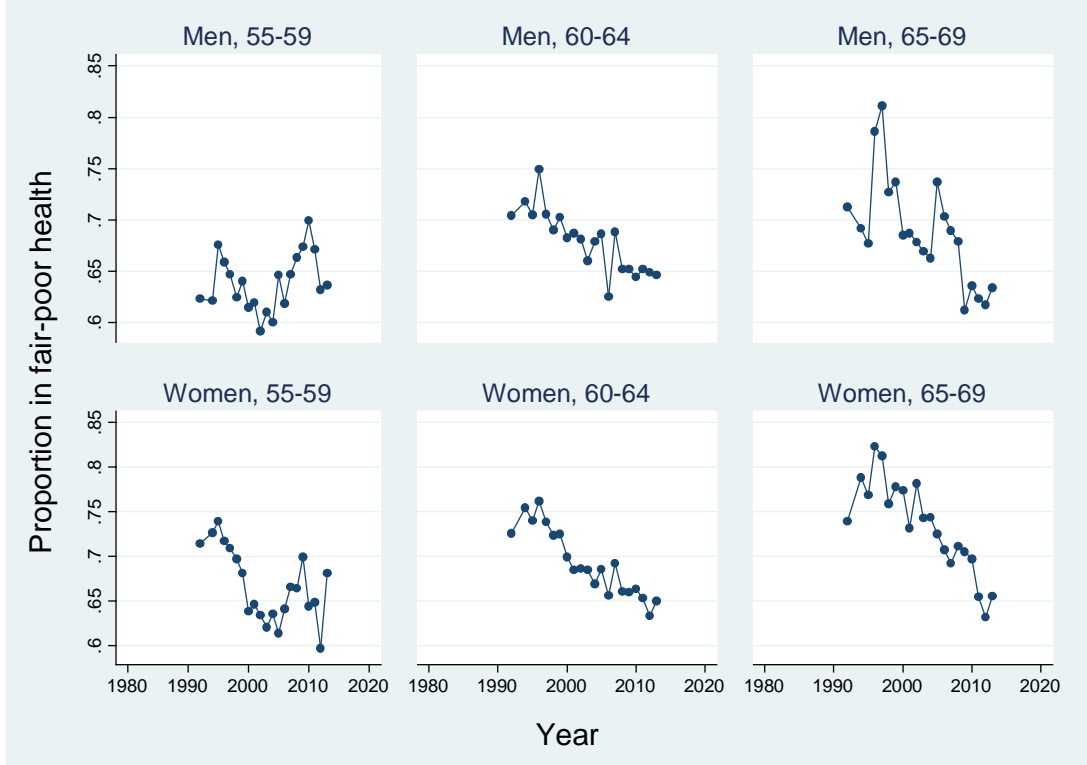

Source: GSOEP 
Figure 19 Percentage with high-school diploma by age group and gender, 1984-2013

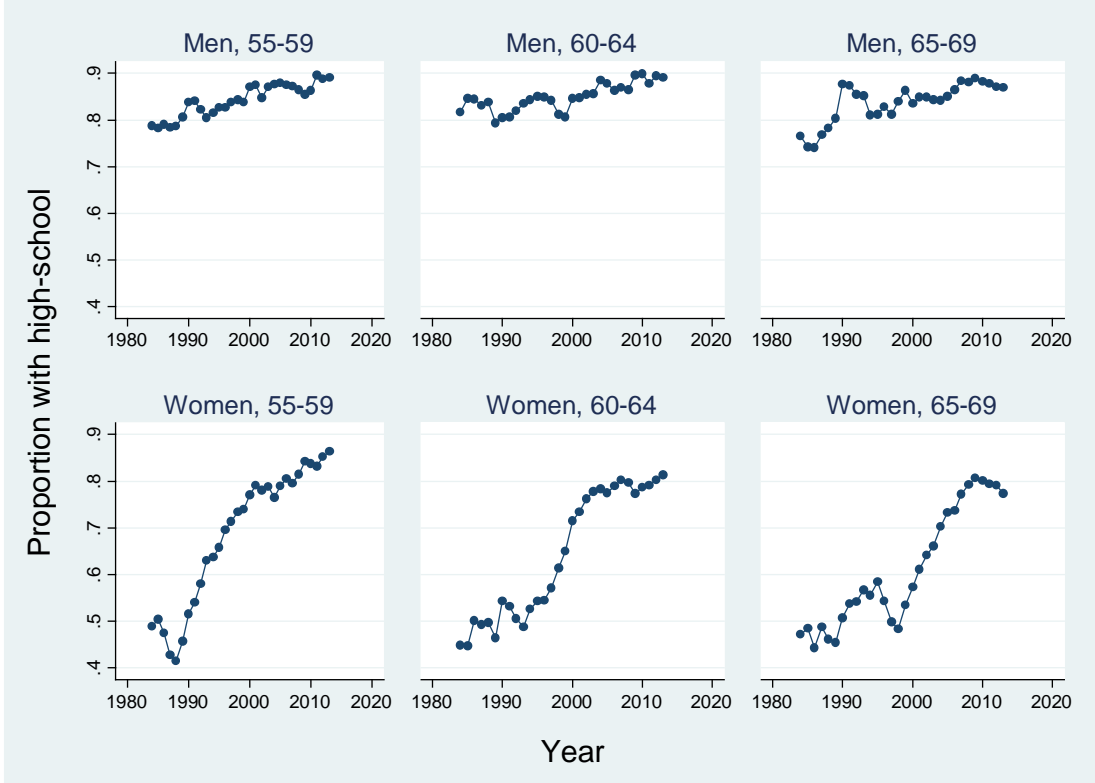

Source: GSOEP 
Figure 20 Percentage with college degree by age group and gender, 1984-2013

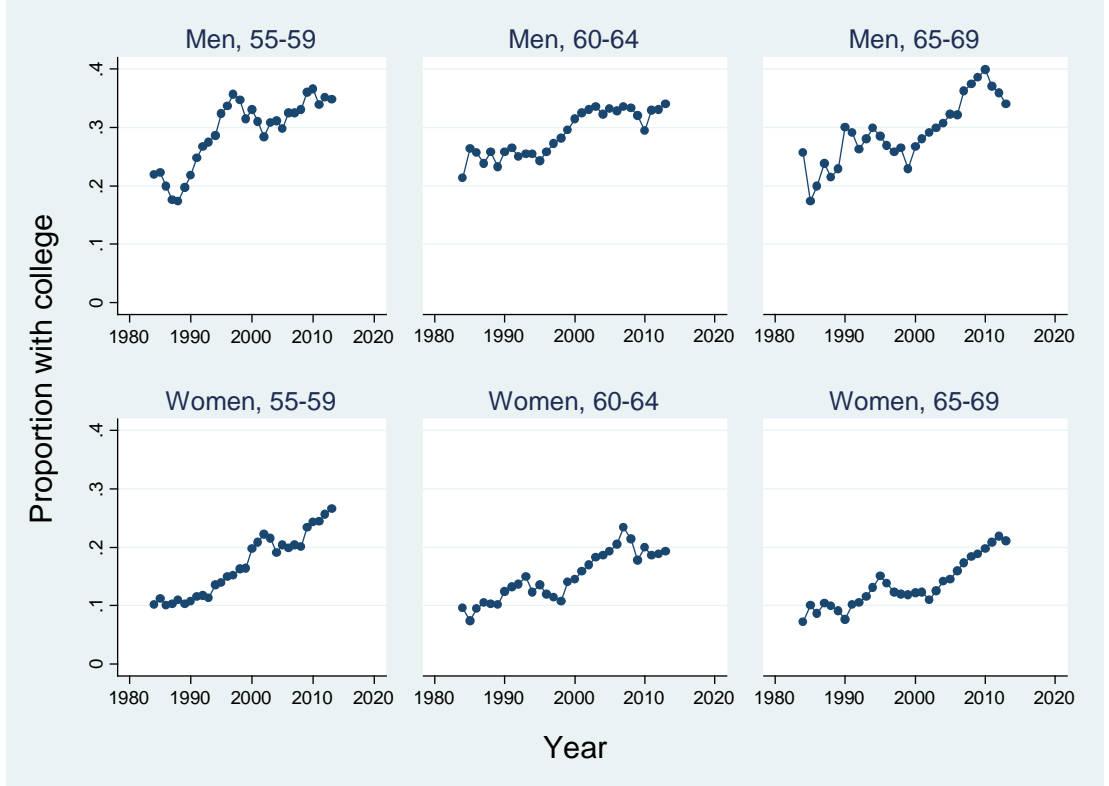

Source: GSOEP 
Figure 21 Unemployment rate of men, 1970-2014

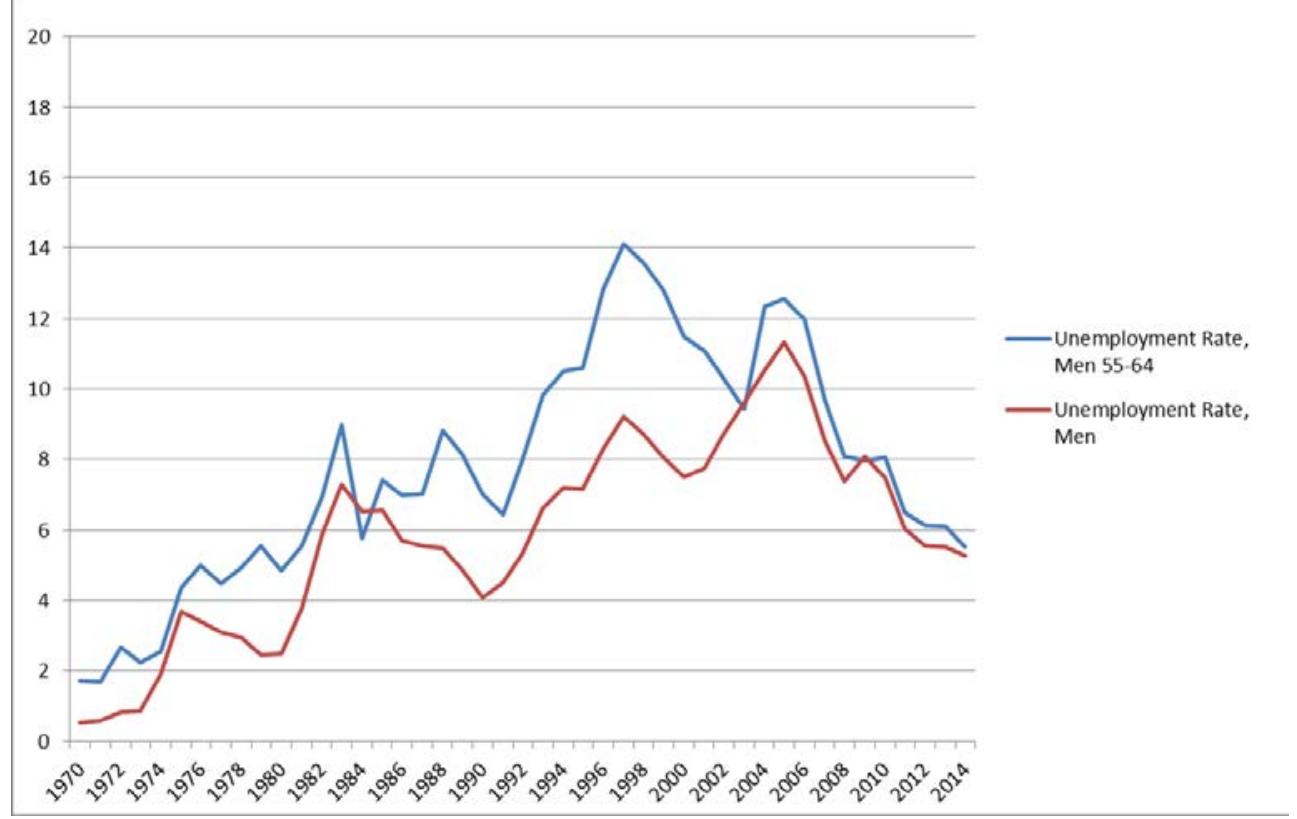

Source: OECD 
Figure 22 Unemployment rate of women, 1970-2014

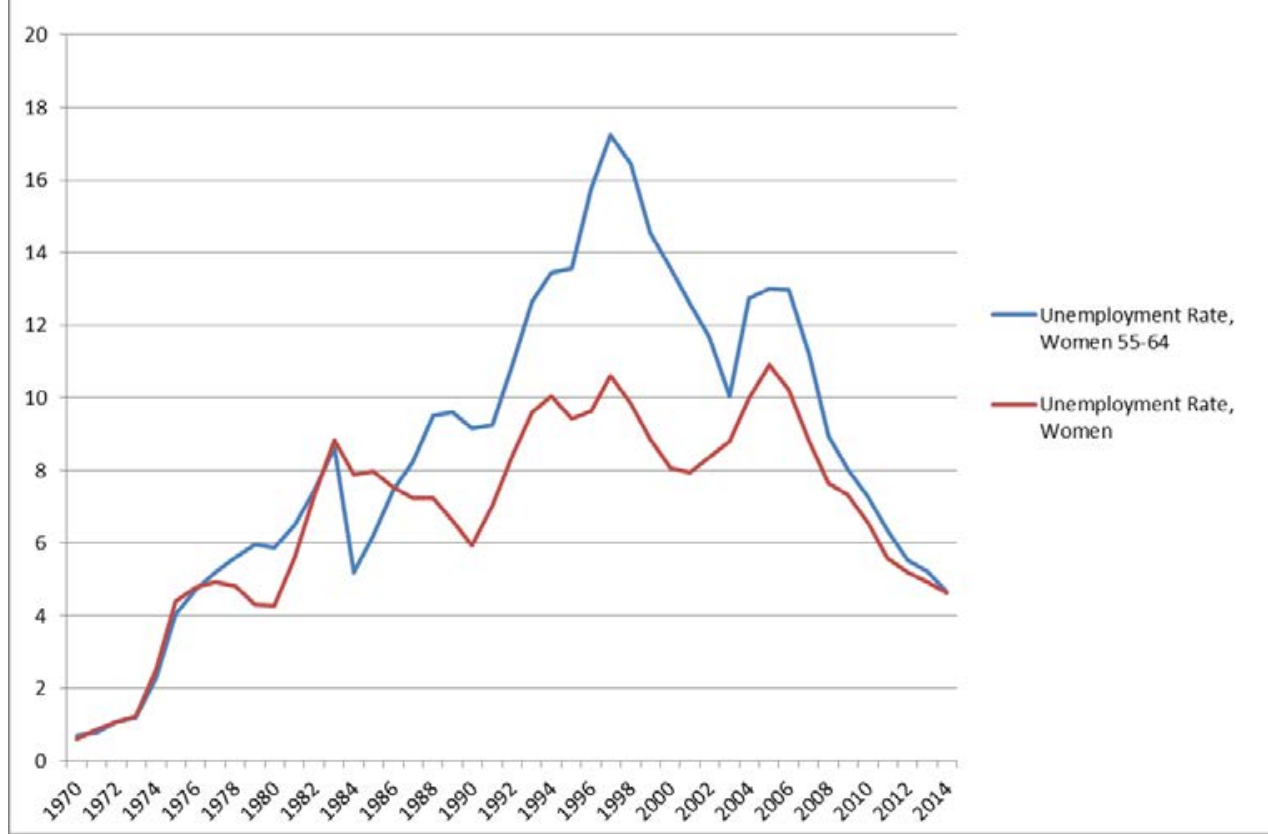

Source: OECD 
Figure 23 Median gross monthly wages by gender (2010 euro), 1984-2013

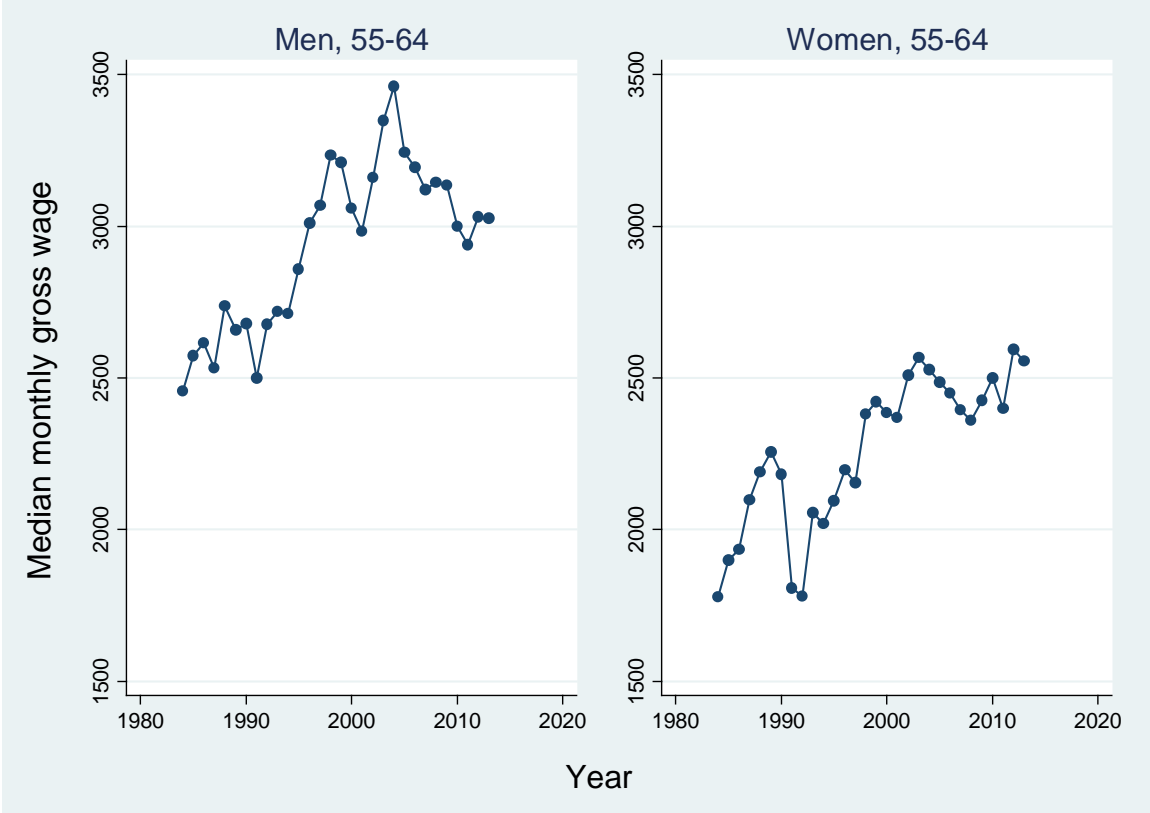

Source: GSOEP 
Figure 24 Distribution of occupations by gender, 1984 and 2013

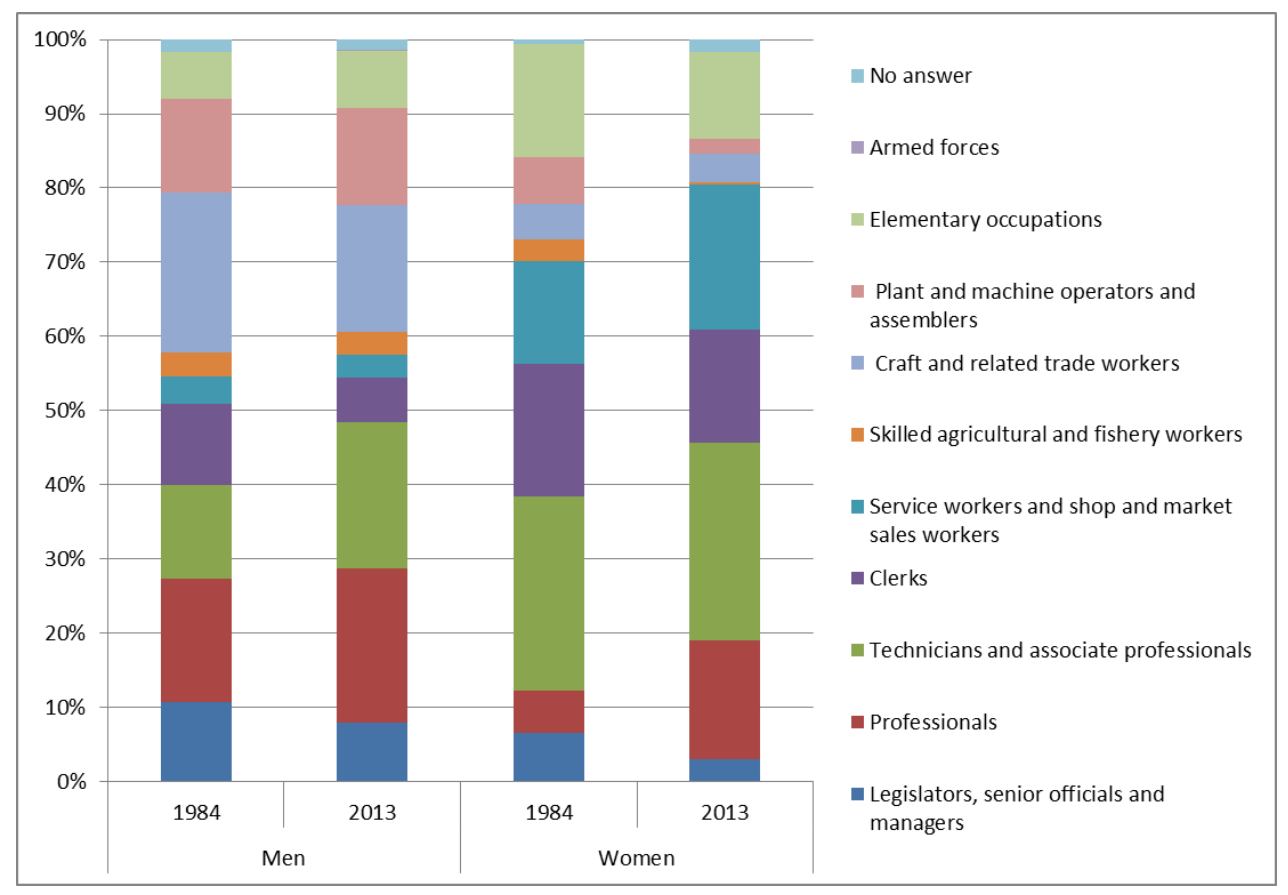

Source: GSOEP 
Figure 25 Median monthly wages at age 55-69 as a percentage of median monthly wages at age 25-54

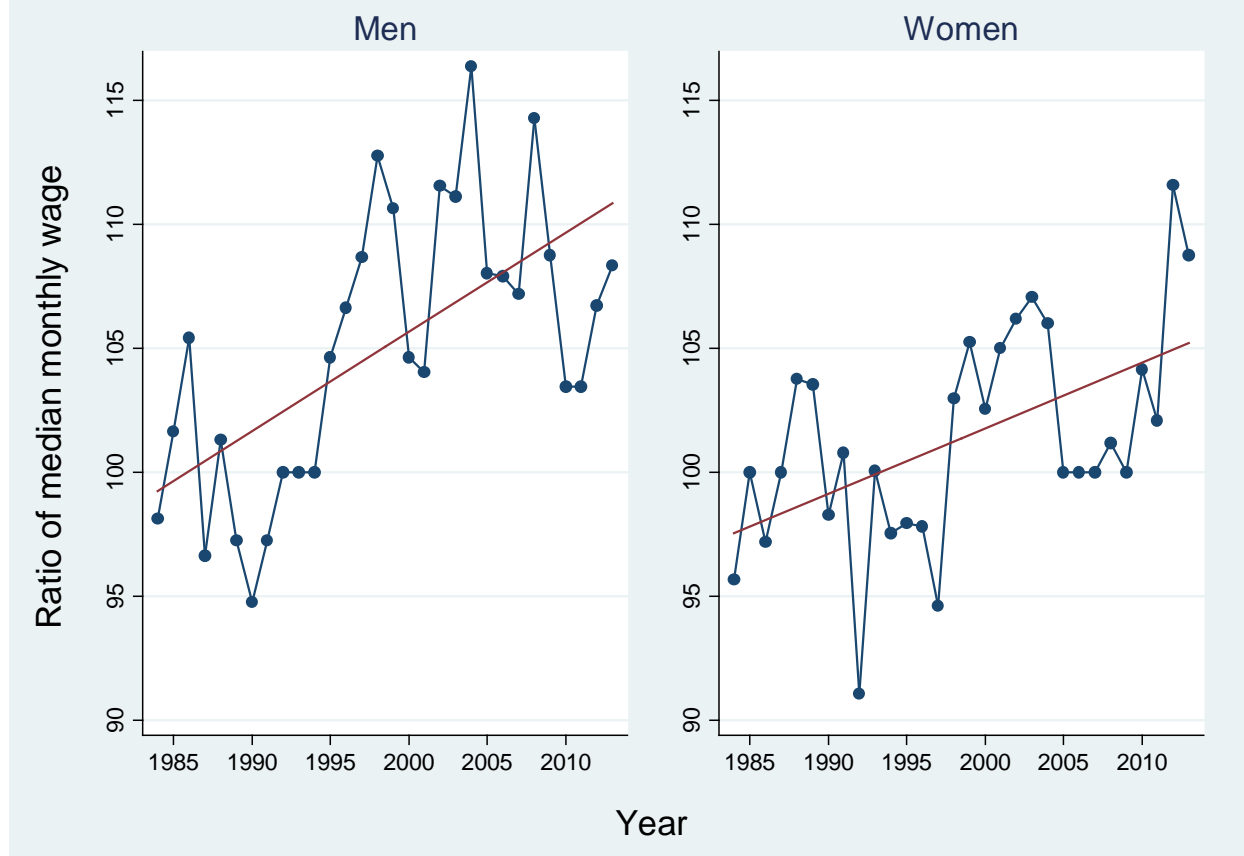

Source: GSOEP 
Figure 26 LFP of individuals aged 60-64, by gender and marital status

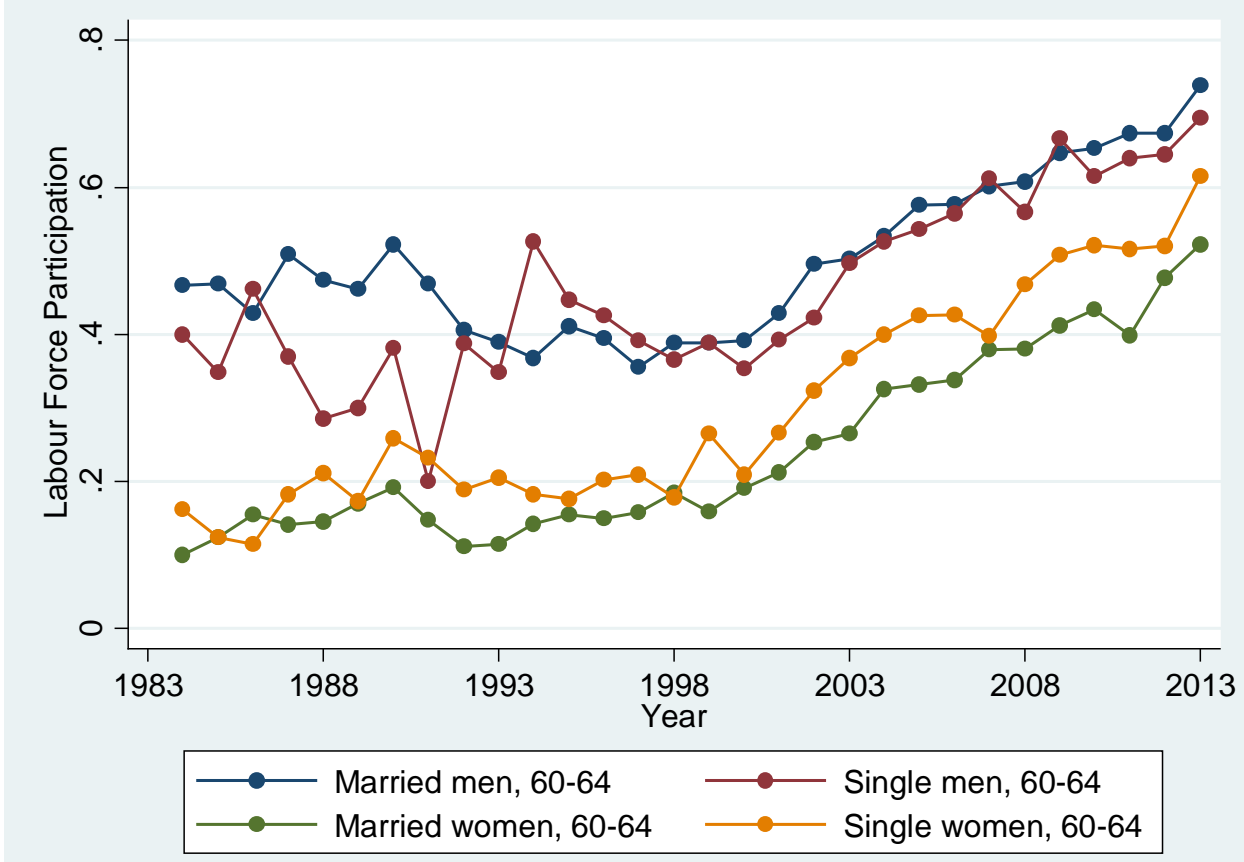

Source: GSOEP 
Figure 27 Counterfactual labor force participation of men of age 55-64, 1984-2013

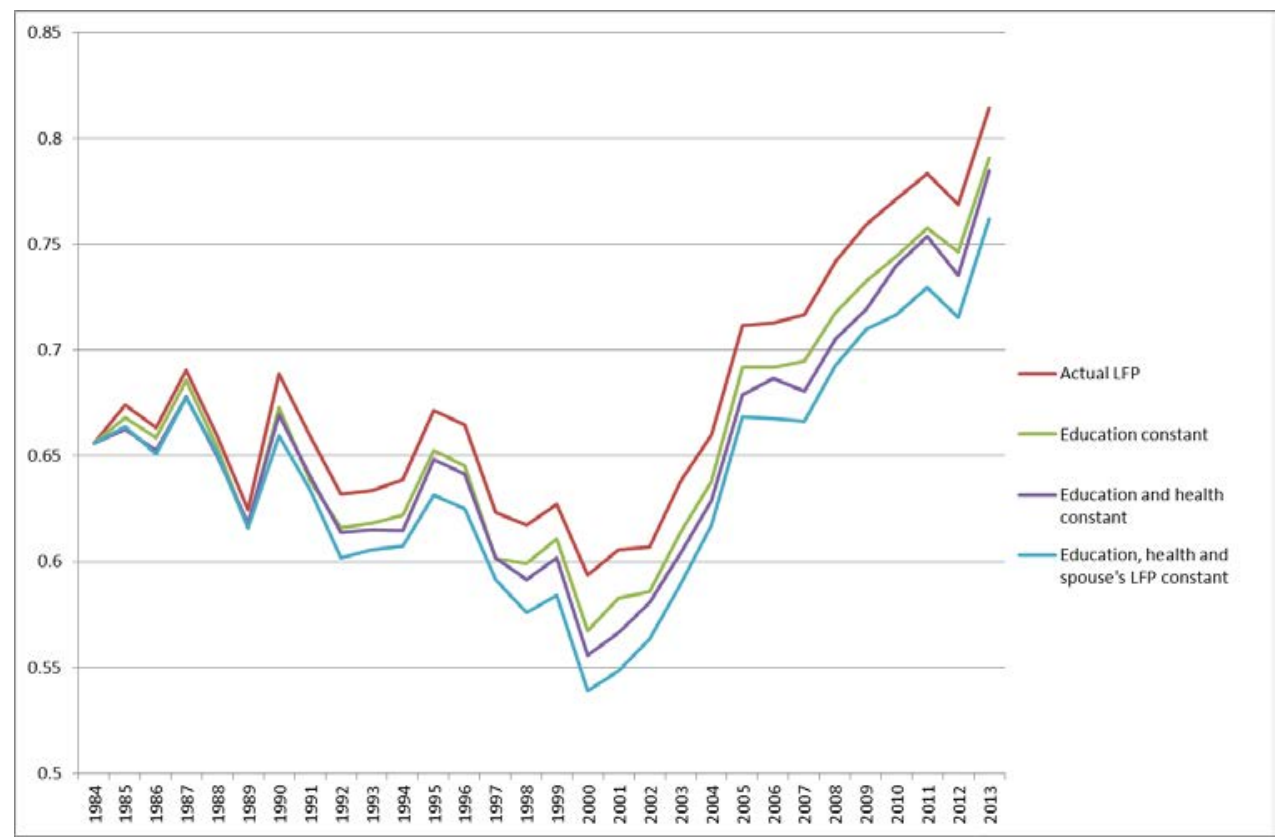

Source: GSOEP 
Figure 28 Counterfactual labor force participation of women of age 55-64, 1984-2013

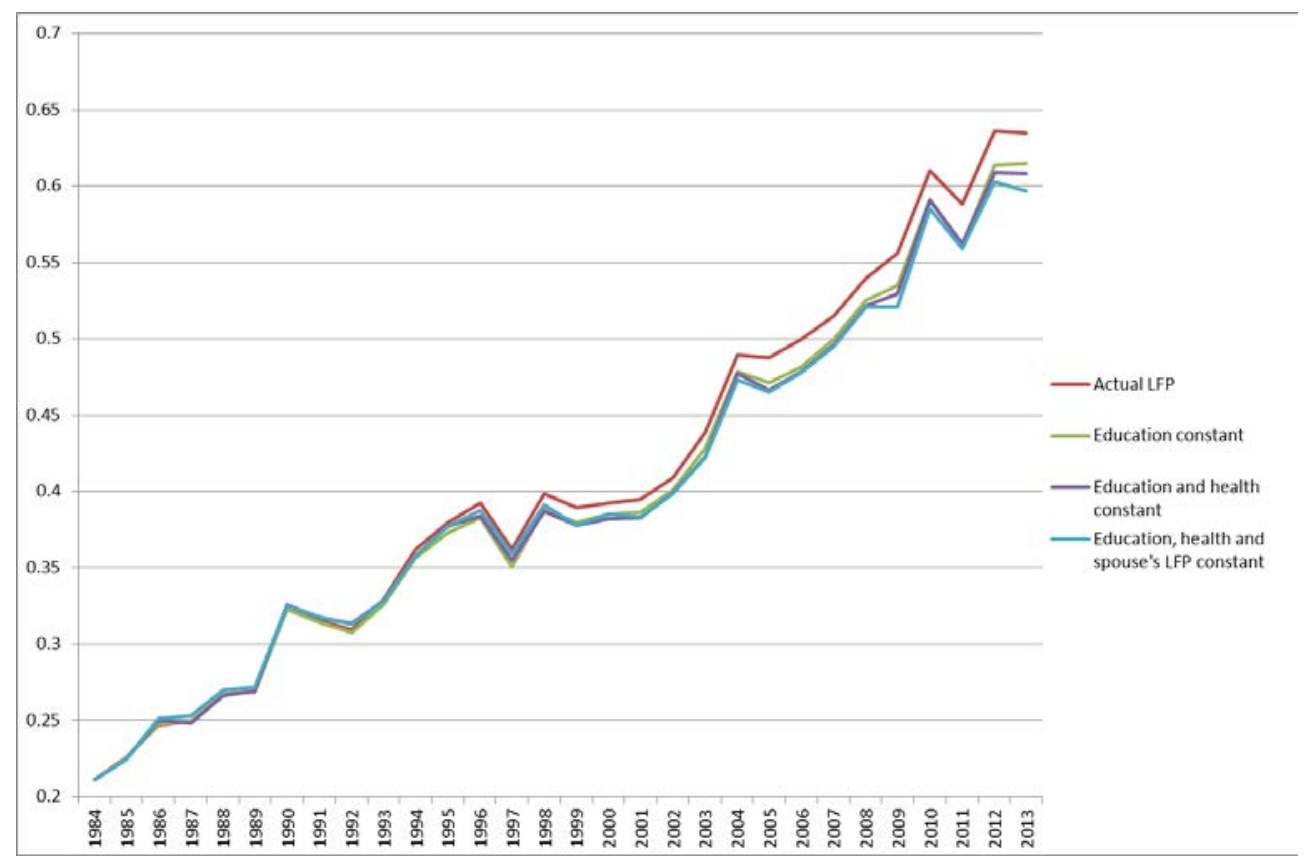

Source: GSOEP 
Figure 29 Counterfactual labor force participation of men of age 55-64 (reverse order), 1984-2013

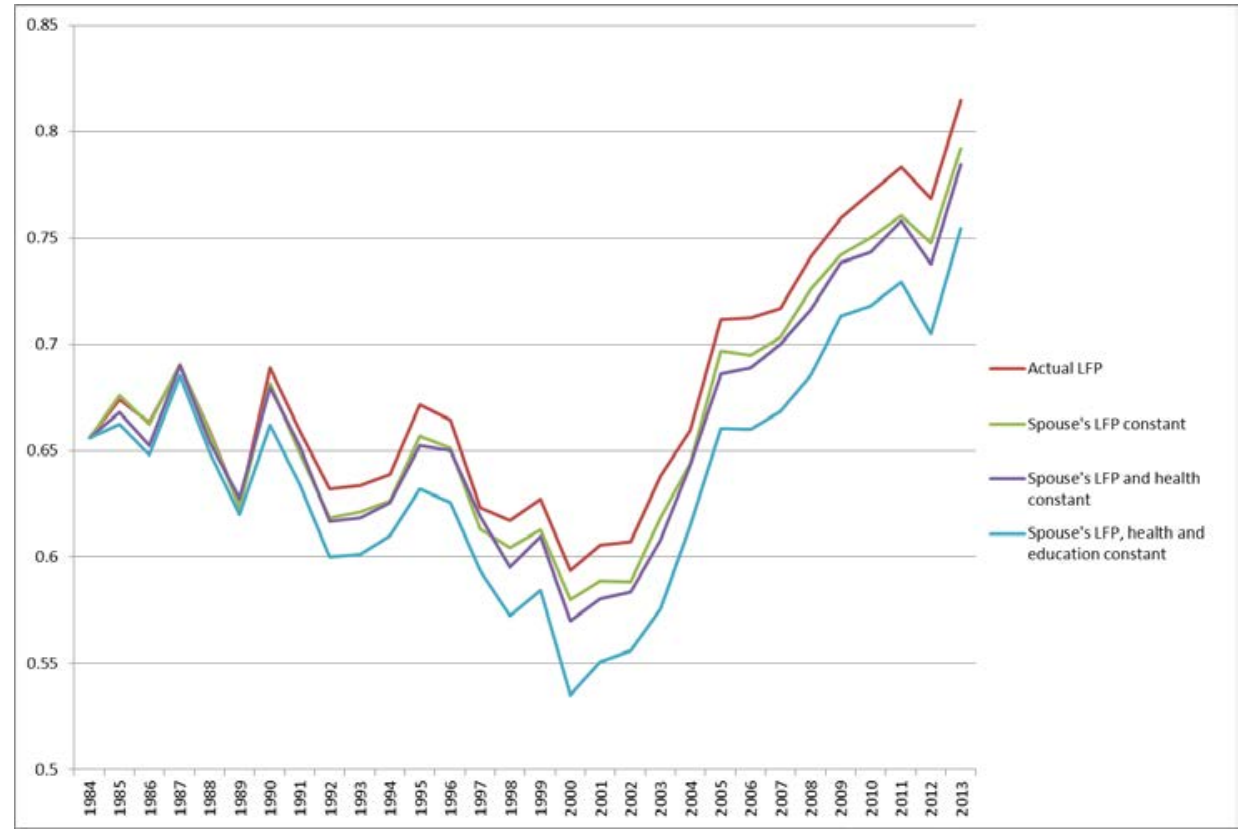

Source: GSOEP 
Figure 30 Counterfactual labor force participation of women of age 55-64 (reverse order), 1984-2013

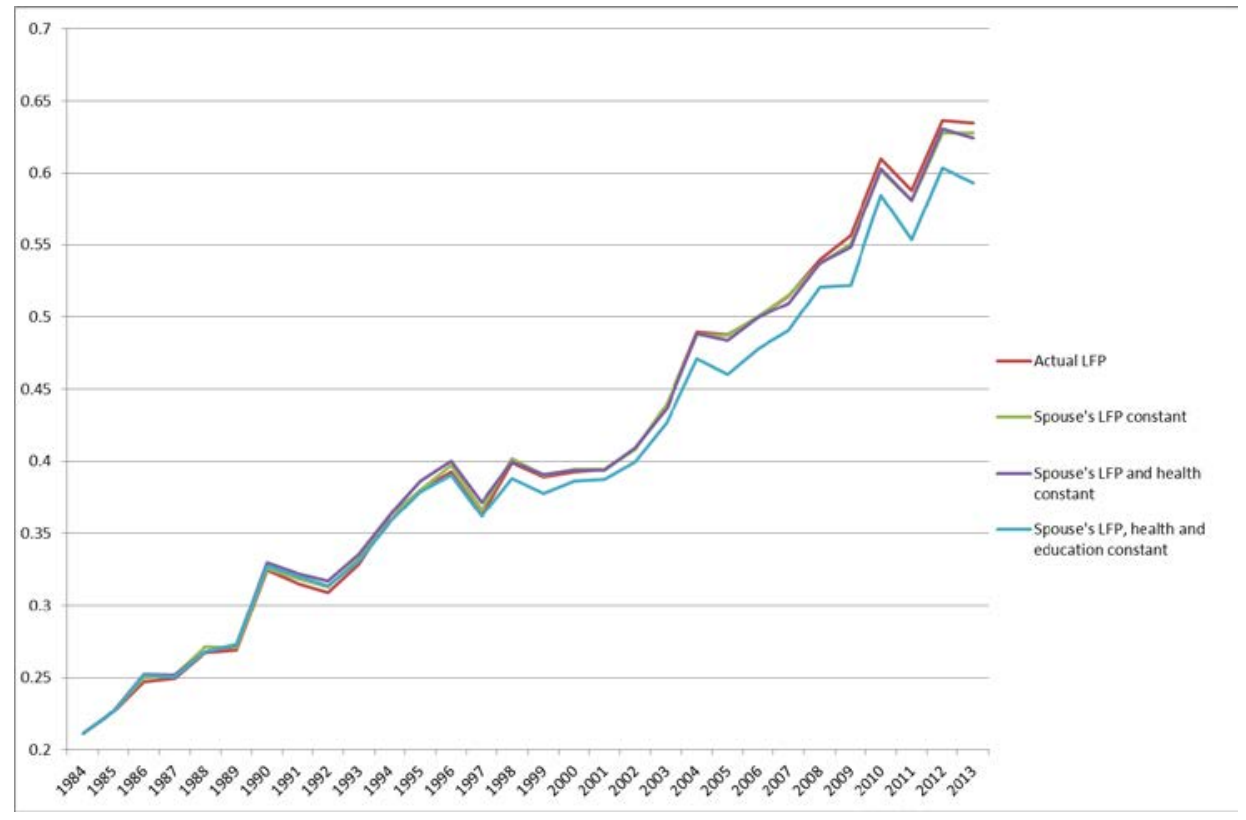

Source: GSOEP 


\section{References}

Blinder, A. S. (1973). Wage discrimination: reduced form and structural estimates. Journal of Human Resources, 436-455.

Börsch-Supan, A., Bucher-Koenen, T., Kluth, S., Haupt, M., \& Goll, N. (2015). Vor-und Nachteile höherer Flexibilität als Instrument zur Erhöhung der Beschäftigung Älterer. MEA Discussion paper 06-2015.

Börsch-Supan, A. H., Coppola, M., \& Reil-Held, A. (2012). Riester pensions in Germany: design, dynamics, targetting success and crowding-in (No. w18014). National Bureau of Economic Research.

Börsch -Supan, A., \& Schnabel, R. (1999) Social security and retirement in Germany. Ch. In Social Security and Retirement around the World (p. 135 - 180). University of Chicago Press.

Börsch-Supan, A., \& Schnabel, R. (2010). Early retirement and employment of the young in Germany. In Social Security Programs and Retirement around the World: The Relationship to Youth Employment (pp. 147-166). University of Chicago Press.

Börsch-Supan, A., Schnabel, R., Kohnz, S., \& Mastrobuoni, G. Micro-modeling of retirement decisions in Germany. Ch. 5 in Social security programs and retirement around the world: Microestimation (pp. 285-344). University of Chicago Press, 2004.

Börsch-Supan, A., and H. Jürges. Disability, Pension Reform, and Early Retirement in Germany. Ch. 7 in Wise. Diss. D.(ed.): Social Security Programs and Retirement around the World: Historical Trends in Mortality and Health, Employment, and Disability Insurance Participation and Reforms. University of Chicago Press, 2012.

Börsch-Supan, A. H., \& Wilke, C. B. (2006). The German public pension system: How it will become an NDC system look-alike. Pension Reform: Issues and Prospects for Non-Financial Defined Contribution (NDC) Schemes, R. Holzmann and E. Palmer, Eds. The World Bank, Washington, DC, 573-610. 
Brenke, K. (2009). Real Wages in Germany: Numerous years of decline. German Research Institute for Economic Research, Weekly Report 28(5): 193-202. Available at: http://www.diw.de/documents/ publikationen/73/diw_01.c.342371.de/diw_wr_2009-28.pdf

Burtless, G. (2013). Can Educational Attainment Explain the Rise in Labor Force Participation at Older Ages?. Issue in Brief, 13-13.

DiNardo, John, Nicole M. Fortin, and Thomas Lemieux. 1996. Labor market institutions and the distribution of wages, 1973-1992: A semiparametric approach. Econometrica 64, no. 5:1001-44.

Fortin, N., Lemieux, T., \& Firpo, S. (2011). Decomposition methods in economics. Handbook of labor economics, 4, 1-102.

Jürges, H., Thiel, L., \& Börsch-Supan, A. (2016). Healthy, Happy, and Idle: Estimating the Health Capacity to Work at Older Ages in Germany. In Social Security Programs and Retirement Around the World: The Capacity to Work at Older Ages. University of Chicago Press.

Juerges, H., Thiel, L., Bucher-Koenen, T., Rausch, J., Schuth, M., \& Börsch -Supan, A. Health, financial incentives, and early retirement: Micro-simulation evidence for Germany Ch. 7 in Wise. Diss. D.(ed.): Social Security Programs and Retirement around the World: Disability Insurance Programs and Retirement. University of Chicago Press, 2016.

Oaxaca, Ronald. 1973. Male-female wage differentials in urban labor markets. International Economic Review 14, no. 3:693-709.

Schirle, T. (2008). Why have the labor force participation rates of older men increased since the mid-1990s?. Journal of Labor Economics, 26(4), 549-594.

Statistisches Bundesamt (2009), Germany's population by 2060 - Results of the 12th coordinated population projection, Federal Statistical Office. Available at: https://www.destatis.de/EN/Publications/Specialized/Population/GermanyPopulation2060.pdf?_ _blob=publicationFile 


\section{Appendix: Data sources}

All data refer to former West-Germany before 1991 and to reunited Germany afterwards:

- Mortality Data: Human Mortality Database (www.mortality.org)

- Labor force participation (where indicated) and unemployment rates: OECD (https://stats.oecd.org/)

- Average retirement age and retirement pathways: Forschungsportal der Deutschen Rentenversicherung (http://forschung.deutsche-rentenversicherung.de/ )

- All other data: German GSOEP, various waves (www.diw.de/GSOEP/en) 